laciones jurídicas, está, como tal, abierto ya de antemano, incluso allí donde formas cosificantes del trato y violaciones del derecho puedan producir ocasionalmente, en el nivel de los casos particulares, efectos incompatibles con las presuposiciones que hacen posible la propia realización exterior de la libertad. Y, justamente, dado que también las formas cosificantes del trato con los demás y las violaciones de sus derechos sólo pueden ser posibles en virtud de la misma libertad contra la que atentan, hay buenas razones para suponer, con Fichte, que su propia existencia, lejos de retrotraernos sin más al nivel del mero acontecer natural, reafirma, más bien, por vía negativa, un hecho tan elemental como decisivo, a saber: que en tanto decidimos y actuamos, de la forma que fuera en cada caso, hemos dado siempre ya el paso que nos hace trasponer el imponente pórtico que da entrada a un reino nuevo y completamente diferente del acontecer, dotado de su propia constitución y sus propias leyes, que no es otro que el reino de la libertad. 


\title{
Dasein, personeidad, intersubjetividad y persona-núcleo (II). La estructura trascendental intelectiva después de Heidegger, en Zubiri, Apel y Polo
}

\author{
Dasein, personality, inter-subjectivity and nucleus-person (II). \\ The intellective transcendental structure after Heidegger, \\ in Zubiri, Apel and Polo
}

Carlos Ortiz de Landázuri Universidad de Navarra, Pamplona cortiz@unav.es

\section{Resumen}

Se analiza el modo comprensivo de concebir el Dasein por parte de Heidegger al caracterizarlo como el principio relacional intelectivo de los entes en general. Especialmente cuando se le asignó una efectiva pertenencia a una estructura transcendental entitativa como "ser en el mundo", sin por ello dejar de ejercer sus funciones intelectivas. Al menos así ocurrió en la forma como Zubiri, Apel y Polo concibieron sus respectivas nociones de personeidad, intersubjetividad o co-subjetividad y persona-núcleo, en estrecha dependencia respecto del modo como el primero interpretó, ya sea el hombre anónimo o la persona auténtica. Pero, a pesar de compartir este punto de partida, cada uno de estos filósofos siguió concibiendo de distinta manera la respectiva inteligencia intelectiva relacional, según se le atribuyeran una mayor capacidad de comprenderse con autenticidad a uno mismo y a los demás entes. Por su parte, el artículo pretende defender la complementariedad de las respectivas propuestas, aunque de momento sea un problema que se deja abierto.

Palabras clave: comprensión, inteligencia, persona, co-subjetividad, ser en el mundo, núcleo del saber

\section{Abstract}

In this article Heidegger's Dasain is analysed and characterised as 'intelective relational principle' of entities in general. This applies particularly when a factive belonging to a 'transcendental entitative structrure' is affirmed, though without stopping to exert intelectual functions. Such is the case for the philosophers Zubiri, Apel, and Polo, as the conceived their own notions of 'personeity', 'intersubjectivity' (or co-subjectivity) and nucleous-person, all these in close surrogacy to Heideg- 
ger's anonymous man or authentic person. However, even if they shared this starting point, each of these philosophers kept conceiving in a different way the relational intellective intelligence, as they attributed a higher capacity of knowing oneself authentically as well as the other entities. In addition, the article aims to uphold the complementarity of each proposal, even though it leaves somehow the problem open to further discussion.

Keywords: understanding, intelligence, person, co-subjectivity, being in the world, knowledge's nucleus

\section{El lugar de la persona en la estructura intelectual intelectiva}

Uno de los grandes debates en la filosofía contemporánea ha sido la determinación del lugar preciso de la persona en la estructura transcendental, que a su vez hace posible la intelección del mundo, de los demás y de su respectivo fundamento último. ${ }^{1}$ Especialmente cuando el primer Heidegger en Ser y tiempo insertó al Dasein en la estructura transcendental de la comprensión del ente, con una pretensión muy precisa: garantizar que todo hombre verdaderamente auténtico pudiera llevar a cabo una posible apertura óntica de su "ser en el mundo" respecto de un horizonte ilimitado ontológico de un "ser de los entes" donde pudieran fundamentarse todos por igual. De todos modos el propio Heidegger reconstruyó simultáneamente una intransitable diferencia óntico-ontológica que acabó impidiendo que el Dasein pudiera ser capaz de fomentar una apertura ilimitada a todos los demás entes, incluido el "ser de los entes", sin restricción alguna. De todos modos siempre le quedaría al Dasein la capacidad de relacionarse con el resto de los entes, al modo como el hombre anónimo inauténtico se relaciona de un modo mancomunado con los demás Dasein, ya sea a través de las esencias o del lenguaje, aunque sin poderse ya hacer falsas ilusiones de alcanzar un posible conocimiento a través de la existencia compartida que en cada caso mantienen con el "ser de los entes". En cualquier caso, el último Heidegger tampoco pudo evitar que esta misma relación con los demás Dasein se volviera una simple relación unilateral y desestructurada, donde tampoco cabe un pleno desarrollo de la sensibilidad, de la racionalidad, de la voluntad o del lenguaje, dada la imposibilidad de otorgarles el grado de apertura existencial que en principio ahora se les exige. De este modo el último Heidegger acabaría concibiendo al Dasein como si se tratara un sujeto postmoderno desestructurado, sin tampoco poder adoptar la actitud coherente que hubiera cabido esperar respecto de sí mismo. Máxime

\footnotetext{
1 Cruz Cruz, J., Dar y agradecer. El eje interpersonal de la intimidad, Pamplona: autoedición, 2015.
} 
cuando ya no es posible asignarle una efectiva capacidad de llegar comprenderse de un modo cada vez mejor desde un horizonte existencial cada vez más abierto, sino simplemente de un modo esencialista diferente. ${ }^{2}$

Por su parte, Zubiri, Apel y Polo trataron de prolongar y de desactivar algunas dificultades surgidas en las propuestas de Heidegger, aunque cada uno lo hiciera en sentidos distintos. Zubiri y Apel tratando de desarrollar las posibilidades heurísticas que aún quedaron abiertas en Ser y tiempo para el hombre inauténtico, ya sea mediante una mejor fundamentación de la esencia de cada uno de los entes, ya sea mediante una mejor justificación del uso compartido del lenguaje ordinario. En cambio Polo trataría de mostrar más bien la posibilidad de prolongar el proyecto originario del primer Heidegger, en la forma propuesta por la persona auténtica, sin condenarlo precipitadamente al fracaso, como acabaría ocurriendo en su caso. En cualquier caso Zubiri, Apel y Polo siguieron manteniendo un acuerdo fundamental respecto del proyecto programático inicial propuesto por el primer Heidegger en Ser y tiempo, aunque por diversos motivos acabaría desistiendo de llevarlo a cabo. ${ }^{3}$

A este respecto, Zubiri trató de prolongar las propuestas del primer Heidegger en Ser y tiempo, aunque fuera siguiendo una línea esencialista que previamente Heidegger había criticado. De hecho Heidegger rechazaría esta actitud por considerarla más propia del hombre anónimo inauténtico, aunque finalmente volvería a ser retomada de un modo no deseado una vez reconocido el fracaso de su inicial proyecto programático. En este sentido Zubiri también trataría de insertar a la persona o personeidad en la estructura transcendental de la intelección del ente, tratando de evitar las dificultades con las que se encontró el primer Heidegger. En este sentido tomó como punto de partida la doble dimensión talitativa o quidditativa, por un lado, y la transcendental, por otro, que a su modo de ver presentan "de suyo" las esencias, ya sean cerradas o abiertas, con anterioridad a cualquier referencia a los conceptos o al propio lenguaje. De este modo Zubiri justificó la doble constructividad de una estructura quidditativa y a la vez transcendental, que a su modo de ver debería perseguir el ejercicio de una personeidad verdaderamente abierta, tanto respecto de las esencias en general como respecto a las demás personas en particular. Sólo así se lograría explicar el doble carácter existencial y a su vez de realidad que la personeidad asigna mancomunadamente a las respectivas esencias, con anterioridad del uso que por su parte la inteligencia pueda hacer de los conceptos o del propio lenguaje. De todos modos Zubiri tampoco pudo evitar una creciente dependencia unilateral que el uso quidditativo de las esencias cerradas y abiertas a su vez mantiene respecto de una inteligencia sentiente,

Wilson, E. O., El sentido de la existencia humana, Barcelona: Gedisa, 2016.

3 Hügl, A., Von der Schwierigkeit, vernünftig zu sein, Basel: Schwabe, 2016. 
sin tampoco terminar de justificar las limitaciones que esta exigencia genera. Por eso tampoco pudo admitir una efectiva apertura de la racionalidad, de la voluntad, de la propia ética o del uso compartido del lenguaje, respecto de un uso verdaderamente transcendental de las esencias, como en principio se había postulado en su proyecto inicial. En cualquier caso, las propuestas de Zubiri tendrían un coste evidente: la imposible asignación a dicha personeidad de una mejor fundamentación mancomunada respecto del alcance verdaderamente transcendental otorgado especialmente a la personeidad abierta, y no simplemente de un modo diferente respecto de algunas quiddidades cerradas más o menos útiles. ${ }^{4}$

Por su parte Apel también trató de prolongar las propuestas del primer Heidegger en Ser y tiempo, aunque fuera siguiendo una línea semiótica que previamente Heidegger había criticado. De hecho el primer Heidegger también rechazaría esta actitud semiótica por considerarla más propia del hombre anónimo inauténtico, aunque al final fuera el único modo factible al que se vería obligado a recurrir en la situación tan desesperada donde el mismo se acabó instalando. En efecto, según Apel, Heidegger debería haber renunciado desde un principio a las pretensiones tan desorbitadas que el hombre auténtico se debería proponer respecto de una posible superación de la diferencia óntico-ontológica que en su caso se establece entre los entes y el "ser de los entes". Por eso se debería haber conformado en su lugar con un objetivo más accesible y a la larga más efectivo, como al final no tuvo más remedio que acabar aceptando, a saber: tratar de desarrollar al máximo la doble dimensión histórico-vitalista o pragmático-transcendental que alternativamente Dilthey y Peirce asignaron a la interpretación de la utilidad pragmática de los acontecimientos mundanos por parte del hombre cotidiano de cada época histórica, aunque con una diferencia, a saber: según Apel, en ningún caso la persecución de esta segunda meta más accesible se debe interpretar como una renuncia al logro de aquella otra estructura transcendental hermenéutica de la autocomprensión del ser más profunda antes propuesta por Heidegger, sino simplemente como un modo más adecuado de llevarla a cabo. De este modo no se podría garantizar ya una imposible comprensión del "ser de los entes", que inicialmente se propuso como un requisito existencial para que el Dasein pudiera llegar a comprenderse a sí mismo. Sin embargo, se podría justificar al menos el postulado de una comunidad ideal de comunicación con la pretensión de poder alcanzar un "consensus omnium" entre todos los posibles afectados. De todos modos Apel tampoco habría podido evitar que los distintos cosujetos semióticos se acabaran insertando en dicha estructura transcendental hermenéutica a través de un uso mancomunado del lenguaje. De este modo

${ }^{4}$ Grygiel, S., Discovering the Human Person. In Conversation with John Paul II, Grand Rapids (MI): W. B. Eerdmans, 2014. 
se volverían a defender algunas de las propuestas unilaterales anteriormente formuladas por el hombre anónimo inauténtico que inicialmente Heidegger tanto había criticado. En cualquier caso, Apel tampoco habría podido admitir una efectiva apertura de la sensibilidad, de la racionalidad, de la voluntad o de la propia ética, así como de los distintos usos cotidianos del lenguaje, respecto de una inalcanzable comunidad ideal de comunicación donde en principio todo este conjunto de facultades se debería remitir, cuando cada una reclama en la práctica un procedimiento autónomo de justificación. A este respecto su noción de co-sujeto hermenéutico mantiene muchas similitudes con la subjetividad postmoderna desestructurada del último Heidegger, por mucho que reiteradamente Apel niegue esta posibilidad. En cualquier caso las propuestas de Apel tendrán un coste evidente: Apel seguiría sin poder garantizar la asignación a dicha cosubjetividad de una efectiva capacidad de comprometerse mancomunadamente respecto de dicha comunidad ideal de comunicación, y no simplemente de un modo consensuado fácticamente diferente. ${ }^{5}$

Finalmente, Polo trataría de mostrar más bien la posibilidad de prolongar el proyecto originario de Heidegger, sin condenarlo precipitadamente al fracaso, como al menos sucede en Ser y tiempo. Por eso trató de insertar a la persona-núcleo en la estructura transcendental de la intelección del ente, prolongando las propuestas de Heidegger. Sin embargo, a diferencia de Zubiri y Apel, Polo consideró adecuada la doble dimensión óntico-ontológica que, según Heidegger, el hombre auténtico debería asignar a cada uno de los entes. En cualquier caso Polo no propugnó la introducción de aquella nueva doble dimensión quidditativa-transcendental que Zubiri atribuyó a la esencia, ni tampoco por esta otra doble interpretación pragmático-transcendental que Apel propuso del uso semiótico del lenguaje. De todos modos Polo consideró inadecuado el modo como Heidegger fue renunciando progresivamente al logro de aquel inicial objetivo programático óntico-ontológico, dejándose enmarañar en problemas secundarios que le acabarían generando una creciente perplejidad heurística cada vez más paralizante. A su modo de ver, habría llegado incluso a concebirse a sí mismo como un simple hombre anónimo inauténtico, cuando debería haber reaccionado de un modo más propio del hombre auténtico, a saber: utilizando esa creciente parálisis que ahora genera la aparición de esta enigmática perplejidad heurística óntico-ontológica para invertir aquella precipitada reacción inicial. Sólo así podría fomentar en su lugar un profundo realismo metafísico frente al "ser de los entes" y frente al propio "mundo". Pero a su vez también habría conseguido evitar la posterior aparición de una subjetividad postmoderna en sí misma desestructurada, como acabó caracterizando al Dasein en su última época. En cualquier caso no se

5 Gardner, S.; Grist, M., The Transcendental Turn, Oxford: Oxford University Press, 2015. 
debería recurrir a fáciles unilateralidades más propias del hombre anónimo inauténtico, que sólo sirven para esconder aún más los problemas, como también habría terminado ocurriendo en Zubiri o Apel. Eso sí, para lograr este objetivo, el hombre auténtico debería desarrollar en su plenitud el conjunto de hábitos que son propios del núcleo de la persona, ya fueran de naturaleza sensible, intelectual, racional, volitiva, ética o simplemente lingüística. Pero veamos por separado cada una de estas propuestas. ${ }^{6}$

\section{La autocomprensión de la estructura transcendental hermenéutica en Ser y tiempo}

Heidegger en Ser y tiempo - SyT $^{7}{ }^{7}$ (1927) habría localizado la estructura transcendental entitativa donde a su vez se inserta el Dasein, o ser ahí de existente concreto, con unos rasgos muy definidos: dicha estructura debería ser objeto de una autocomprensión relacional hermenéutica respecto de la mediación que el propio Dasein ejerce a la hora de comprender el lugar preciso de cada "ente" en particular respecto del correspondiente "ser de los entes". El hombre auténtico debería así anticipar un posible horizonte transcendental en sí mismo ilimitado desde donde fuera posible una adecuada comprensión existencial de cada ente "en cuanto tal". Se trataría de un requisito imprescindible para que el hombre auténtico pudiera vivenciar desde dentro el drama de su propia existencia, sin conformarse con las interpretaciones meramente esencialistas del hombre anónimo inauténtico. Sin embargo, al formular esta propuesta, tampoco pudo evitar así la aparición de un círculo hermenéutico que ahora se genera de un modo a su parecer vicioso debido a una dificultad añadida en sí misma insuperable, a saber: la carencia de un procedimiento preciso que le hubiera permitido al hombre auténtico determinar los límites existenciales exactos donde se debe situar el respectivo horizonte transcendental ahora configurado por el "ser de los entes". Quisiera o no, el hombre auténtico tendría que anticipar a este respecto una noción ontológica de "ser de los entes" a todas luces improvisada y carente de una adecuada justificación. ${ }^{8}$

Se generó así un segundo debate aún más encrespado que el anterior, al plantearse una cuestión previa todavía más compleja, a saber: el tipo de mediación necesaria que el Dasein debe ejercer para establecer una posible la correlación entre su propio "ser en el mundo" y el respectivo "ser de los entes". Se trata de una mediación óntico-ontológica donde el Dasein o ser-

6 Burgos, J. M., La experiencia integral. Un método para el personalismo, Madrid: Palabra, 2015.

7 Heidegger, M.; Ser y tiempo, Madrid: Trotta, 2003.

8 Gardner, S. Grist, M., The Transcendental Turn, Oxford: Oxford University Press, 2015. 
ahí del existente concreto otorga a cada ente un doble sentido comprensivo-hermenéutico, según sus dos formas posibles de interpretarlo, a saber: o bien el Dasein analiza el lugar que le corresponde a cada ente junto a los otros entes en la respectiva estructura óntica, por el mero hecho de concebirse como un "ser en el mundo"; o bien el Dasein analiza el lugar que le corresponde a ese mismo ente en la estructura ontológica generada a su vez por el "ser de los entes" cuando se pretende abarcarlo y afirmarlo como el fundamento último al que necesariamente se remite cualquier otro "ente" cuando se concibe como tal "ente". Máxime cuando se comprueba cómo esta doble dimensión ónticoontológica viene precedida por una libre interpelación claramente circular ejercida en este caso por el Dasein sobre cada "ente" en concreto, dando lugar a una inevitable alternativa, a saber: o bien, por un lado, se analiza cada "ente" de un modo particular, mediante la anticipación por parte del Dasein de una libre interpretación circular respecto de su posible uso pragmático, como si se tratara de una simple "cosa" útil entre otras muchas factibles. Se justifica así una primera alternativa como si se tratara de una simple posibilidad óntica, que a su vez es propia del hombre anónimo inauténtico, que vive de espaldas al drama de la existencia que genera la simple referencia al "ser de los ente"; o bien, por otro lado, se analiza a cada "ente" desde el correspondiente horizonte transcendental cada vez más ilimitado, que a su vez permite establecer una creciente apertura por parte del Dasein respecto del correspondiente "ser de los entes". Se concibe así esta segunda alternativa como un fundamento verdaderamente ontológico que está sobreentendido tras cada ente, y que es propia del hombre auténtico. De todos modos, tampoco se pudo evitar en esta segunda opción que el Dasein tuviera que seguir ejerciendo una segunda interpretación circular todavía más violenta sobre el propio lenguaje, dado que para alcanzar una comprensión hermenéutica de este alcance verdaderamente transcendental se debería anticipar un tipo de principios ontológicos que, como ahora sucede con el "ser de los entes", tampoco el Dasein habría podido llegar a comprender verdaderamente, aunque se considere un hombre muy auténtico. ${ }^{9}$

En efecto, una vez comprobada la necesidad que tiene el hombre auténtico de remitirse a una estructura transcendental hermenéutica con capacidad de

\footnotetext{
9 Por eso afirmó Heidegger: "Al ser del Dasein le pertenece una autointerpretación (Selbstauslegung) [...]. Si el ser del Dasein es por esencia poder-ser y ser-libre para sus más propias posibilidades, y si el Dasein no existe sino en libertad para ellas o en la falta de libertad frente a ellas, ¿podrá la interpretación ontológica hacer otra cosa que establecer como fundamento posibilidades ónticas (modos de poder-ser) y proyectar esas posibilidades ónticas hacia su posibilidad ontológica? Y si regularmente el Dasein se interpreta a sí mismo desde su estar perdido en los quehaceres del "mundo", ¿no será la determinación de las posibilidades óntico-existentivas logradas en oposición a ello, y el análisis existencial en ellas fundado, la forma de apertura que se ajusta adecuadamente a este ente? ¿No se convierte entonces lo violento del proyecto en una concreta puesta en libertad del contenido fenoménico no disimulado del Dasein?" (SyT, p. 328).
} 
abarcar a todos los entes, también se debería sacar una segunda consecuencia muy precisa: en todos estos casos el propio Dasein debería poder ser objeto de una autocomprensión hermenéutica relacional que fuera capaz de asignarse una libertad transcendental en sí misma ambivalente entre dos posibilidades mutuamente relacionadas, pero antitéticas, a saber: o bien abrirse a una mundanidad óntica cotidiana, donde sólo comparecen los "entes a la mano" o las cosas meramente útiles, sin tampoco tener mayores pretensiones, como sucede en el hombre anónimo inauténtico; o bien fomentar una ilimitada apertura a un horizonte interpretativo cada vez más abierto respecto de un inabarcable "ser de los entes", como debería en todo momento pretender el hombre auténtico, a pesar de tratarse de una pretensión en sí misma inalcanzable. Máxime cuando se comprueba, como en el caso de no admitirse esta segunda posibilidad, tampoco el Dasein podría advertir el peculiar modo hermenéutico conformista de concebir cada "ente" en particular. No podría hacerse cargo de que en la práctica estaría fomentando una actitud utilitaria cotidiana que desde luego no cultiva la más mínima responsabilidad ética ante el drama de la existencia. Se comprueba así que tampoco es posible ya eludir el inevitable círculo hermenéutico de la comprensión que a su vez se genera entre ambas interpretaciones, por muy antitéticas que parezcan. Por ello ya no resulta posible reconocer la inautenticidad de la existencia cotidiana, cuando simultáneamente se comprueba que el hombre auténtico tampoco puede cultivar una ilimitada apertura al "ser de los entes". Por este motivo, Heidegger acabaría otorgando a este círculo hermenéutico de la comprensión un carácter en sí mismo vicioso, dada la imposibilidad cada vez mayor de superar la creciente diferencia óntico-ontológica que se establece entre los "entes" y el respectivo "ser de los entes". Hasta el punto de declararse incapaz de poder superar realmente la visión cotidiana simplemente utilitaria de las cosas del hombre anónimo inauténtico, por muchas ilusiones que el hombre auténtico se haga en sentido contrario. En cualquier caso se debe otorgar al "ente" en general una doble apertura comprensiva, esencial y a la vez existencial, óntica y a su vez ontológica, inauténtica y a la vez auténtica, aunque al final todas estas pretensiones heurísticas se vuelvan heurísticamente estériles. En cualquier caso el Dasein se ve obligado a otorgar a los entes un doble libre sentido cada vez más internamente contrapuesto, según prevalezca un enfoque u otro, aunque al final se acabe imponiendo la peor opción de todas. ${ }^{10}$

\footnotetext{
${ }^{10}$ A este respecto afirma Heidegger: "Pero ¿no tenemos que llegar a la aclaración de la idea de ser en general por medio de la comprensión del ser que es propia del Dasein? Sin embargo, ésta no puede ser originariamente comprendida sino sobre la base de una interpretación originaria del Dasein hecha al hilo de la propia existencia. ¿No resulta entonces enteramente evidente que el problema de la ontología fundamental se mueve en un 'círculo'? Ya hicimos ver, con ocasión del análisis de la estructura del comprender en general, que lo censurado con la inadecuada expresión de 'círculo' pertenece a la esencia y al carácter distintivo del comprender mismo" (SyT, p. 330).
} 
Heidegger advirtió así el inevitable círculo hermenéutico vicioso que de hecho se establece a la hora de interpretar la estructura transcendental entitativa donde el Dasein se encuentra inserto. Sin embargo, consiguió comprobar que el Dasein se puede otorgar a sí mismo un doble libre sentido, a saber: o bien concebirse como un hombre anónimo igual a una "cosa" sólo útil para los demás entes; o bien concebirse desde el ser de los entes como un hombre auténtico con capacidad de reconocer su apertura a los demás "entes" y a los demás Dasein con la ayuda del lenguaje, sin poder ya confundirse con una simple "cosa", ni con un hombre anónimo inauténtico. Se trata a su modo de ver de una prueba irrefutable a favor del carácter absolutamente independiente que tiene la inserción del Dasein en la respectiva estructura constitutiva interna y externa, tanto del "ente" en general como del "ser de los entes" en particular. En este sentido, Heidegger tuvo que atribuir al Dasein una doble autocomprensión relacional hermenéutica de sí mismo y de los demás Dasein, según el tipo de relación óntico-ontológica que en cada caso prevalezca. De hecho, el Dasein puede formular dicha interpelación desde sí mismo, concibiéndose como un hombre anónimo inauténtico igual a los demás Dasein, sin necesidad de presuponer ningún fin externo que esté más allá de su propio ser; o bien el Dasein se puede concebir como un hombre auténtico absolutamente distinto a todos los demás entes, e incluso a los demás Dasein anónimos o inauténticos. En efecto, todo dependerá de la capacidad de interpelación que se otorgue a sí mismo y al resto de los "entes" desde un horizonte transcendental entitativo cada vez más ilimitado. Es decir, un horizonte que desde un principio se remite al correspondiente "ser de los entes", aunque desde un primer momento pueda parecer que se trata de una posibilidad totalmente desmesurada. De todos modos para hacer efectiva esta segunda posibilidad se le presenta una dificultad añadida. En efecto, para llevar a cabo un proceso hermenéutico de apertura de una amplitud tan ilimitada como ésta, el hombre auténtico se tendría que ejercer una violencia todavía mayor sobre el uso habitual del lenguaje. De hecho, el hombre auténtico tendría que prejuzgar como evidente lo que aún no se puede llegar a comprender mediante el recurso habitual a los conceptos, ni al lenguaje. En este sentido, debería presuponer una comprensión precisa del "ser de los entes", así como una adecuada expresión a través del correspondiente lenguaje, cuando resulta una pretensión de suyo imposible. Se trata del problema de la diferencia óntico-ontológica que, como se sabe, Heidegger nunca consiguió superar. ${ }^{11}$

${ }^{11}$ A este respecto afirma Heidegger: “Ahora bien, la 'objeción del círculo' proviene, ella misma, de un modo de ser del Dasein. [...] La comprensión común sólo se ocupa, 'teórica' o 'prácticamente, del ente que puede ser abarcado con la mirada circunspectiva. Lo característico de la comprensión común es que ella cree experimentar tan sólo entes 'de hecho', para poder así sustraerse a una comprensión del ser. No comprende que los entes sólo pueden ser experimentados 'de hecho' si el ser ya ha sido comprendido, aunque sea sin conceptos. 


\section{La estructura óntico-ontológica del Dasein en el primer Heidegger}

De todos modos, Heidegger tampoco pudo evitar que el propio Dasein pudiera acabar trivializando su anterior propuesta relativa a alcanzar un imposible despejamiento del "ser de los entes"; especialmente, cuando se comprobó que tampoco el hombre auténtico podía disponer de unos conceptos adecuados al respecto. Se hizo así más patente la imposibilidad de eludir la posterior mediación de un inevitable círculo hermenéutico en sí mismo vicioso, tanto respecto de la comprensión de los entes en general como respecto del propio Dasein en especial. De hecho, en el primer Heidegger de Ser y tiempo acaba prevaleciendo la interpretación del Dasein como un hombre anónimo inauténtico, es decir, como si se tratara de un "ente" más, junto al resto de los "seres a la mano" o junto a los "otros" simples "seres-ahí" (Dasein) efectivamente existentes. Es cierto que cada Dasein se debería concebir a sí mismo como un hombre auténtico, es decir, como un "ser en el mundo" con una capacidad de comprensión hermenéutica absolutamente singular, distinta a la que tienen los demás entes, precisamente por su capacidad de concebir la inquietante apertura al "ser de los entes". Sin embargo, simultáneamente tampoco puede dejar de concebirse como un hombre anónimo inauténtico; es decir, como un ser ónticamente limitado similar a los demás entes que, sin embargo, se ilusiona con pretensiones de suyo imposibles. ${ }^{12}$

En cualquier caso el Dasein se otorgó a sí mismo un doble libre sentido aparentemente contrapuesto al que anteriormente se asignó al resto de los "entes". En efecto, la apertura al "ser de los entes" permite atribuir al Dasein dos posibles dimensiones óntico-ontológicas aparentemente contrapuestas, a saber: o bien, por un lado, el lenguaje le atribuye al hombre anónimo inauténtico una existencia efectiva similar a la asignada de un modo óntico a cada "ente", en la medida que se afirma como un ente simplemente útil similar a los demás "entes"; y, por otro lado, el lenguaje también le atribuye al hombre auténtico la pertenencia a una realidad ontológica en sí misma ilimitada. Especialmente cuando se reconoce como un "ser en el mundo" que a su vez co-existe junto a los demás "entes", estando de este modo entroncado con un ilimitado "ser de los entes". Con la circunstancia añadida de que la ejecución de este segundo proceso de comprensión hermenéutica sería anterior al primero. En efecto, el propio Dasein no se puede concebir como un "ente" ni

La comprensión común comprende mal el comprender. Y por eso tiene que considerar necesariamente como 'violento' aquello que supera el alcance de la comprensión e incluso la tendencia misma a superarla" (SyT, p. 331).

12 Inwagen, P. van, Existence. Essays on Ontology, Cambridge: Cambridge University Press, 2014. 
como un "ser en el mundo", si el lenguaje previamente no le reconoce su propia co-existencia junto al "ser de los entes" por el mero hecho de ser un "ente". Sólo así sería posible concebir la existencia y la realidad como dos dimensiones del ser en general y del Dasein en particular, como posteriormente también sucederá en Zubiri, Apel y Polo. De todos modos, en todos estos casos se acabará cuestionando el carácter pretendidamente vicioso o virtuoso del círculo hermenéutico que ahora se genera entre ambas dimensiones de los entes. En general se opina que tampoco debería ser necesario llegar a las conclusiones tan derrotistas que propuso Heidegger. De hecho el propio Heidegger también reconoció provisionalmente el pretendido carácter virtuoso de esta misma posibilidad, aunque finalmente la acabara rechazando y la considerara como una virtualidad ilusionante, pero heurísticamente estéril. ${ }^{13}$

Heidegger reconoció así el carácter inconmensurable de la anterior pregunta heurística relativa al posible doble libre sentido óntico y a la vez ontológico que ahora se otorga a una posible comprensión acerca, ya sea del ente, del propio Dasein o del correspondiente "ser de los entes". Máxime cuando se sabe de antemano que cualquier posible propuesta al respecto acabará generando un círculo hermenéutico de interpretación en sí mismo vicioso, por tener que anticipar la comprensión de una noción de "ser de los entes" ya previamente prefijada de antemano. Heidegger admitió así desde un principio la necesidad hermenéutica de anticipar un horizonte transcendental de comprensión cada vez más abierto, con el inconveniente de que tampoco el "Dasein" o ser-ahí del existente concreto, puede aportar argumentos convincentes para justificar este tipo de propuestas hermenéuticas tan ambiciosas. ${ }^{14}$

En este contexto, Heidegger asignará al "Dasein" una comprensión relacional hermenéutica capaz de otorgar a cada "ente", incluido el propio Dasein, un libre doble sentido óntico-ontológico cada vez más contrapuesto. Máxime cuando de antemano se sabe que tampoco se puede pretender dar un salto en el vacío que evite el anterior círculo hermenéutico en sí mismo vicioso que ahora se establece entre el correspondiente punto de partida y de llegada de dicho

\footnotetext{
${ }^{13}$ Por eso afirma: "El ente que llamamos Dasein lo soy cada vez yo mismo, y lo soy como un poder-ser en que está en juego ser este ente. Aunque sin la suficiente precisión ontológica, el Dasein se comprende como estar-en-el-mundo. Y por ser el Dasein de esta manera, comparecen para él entes con el modo de ser de lo a la mano y de lo que está ahí. [...] Sin embargo, él no es tan sólo un algo que está-ahí, sino que, aunque sea en una interpretación mítica y mágica, ya se ha comprendido siempre a sí mismo. Pues de lo contrario no "viviría" en un mito, ni practicaría su magia en ritos y culto. [...] La delimitación de la estructura del cuidado proporcionó la base para una primera distinción ontológica entre existencia y realidad. Esto nos llevó a la tesis: la substancia del hombre es la existencia. [...] Sólo dentro del horizonte de esta idea puede llevarse a cabo la distinción entre existencia y realidad. En efecto, las dos nombran al ser" (SyT, pp. 329-330).

${ }^{14}$ Coriando, P-L.; Röck, T., Perspektiven der Metaphysik im "postmetaphysichen" Zeitalter, Berlin: Duncker und Humblot, 2015.
} 
proceso. De hecho, de aceptar un posible salto de este tipo, lo único que se conseguiría sería poner aún más en evidencia el desconocimiento absoluto de la situación entitativa tan problemática en donde ahora el Dasein se encuentra. En este sentido, la única respuesta factible a la hora de abordar este problema consiste en tomar como punto de partida este mismo círculo hermenéutico, desde donde el Dasein pretende interpelar a todos los "entes", según se adopte un punto de vista óntico u ontológico. Al menos así sucede cuando se trata de indagar del mejor modo posible la justificación de la propia constitución interna, ya sea de cada "ente" en particular, del propio "ser-ahí" del Dasein o del respectivo "ser de los entes". Se trata de un paso obligado que habría que dar a la hora de justificar los respectivos presupuestos de la estructura hermenéutica transcendental que a su vez hace posible los correspondientes procesos de comprensión entitativa. Sin embargo, ahora se opina que se trata de un salto muy pretencioso por ser de imposible ejecución. ${ }^{15}$

En cualquier caso se habría dado un paso de gigante respecto del punto de partida inicial de este proceso. De hecho ya no sería necesario refugiarse en un "yo" inexpugnable carente de cualquier referencia a un mundo circundante, pensando que se trata de una posición autoinmune ante cualquier posible crítica, como pretendían Descartes, Kant o Hegel. De igual modo que tampoco sería necesario pensar que se están tomando excesivas cautelas o que se están haciendo excesivas concesiones, por el simple hecho de tener que remitirse a un "mundo circundante", cuando más bien supondría lo contrario, a saber: en el fondo se está haciendo una propuesta excesivamente timorata por el hecho de tener que admitir un posible reconocimiento del doble libre sentido óntico-ontológico que se debe atribuir a todo "ente". Máxime cuando tampoco se puede concebir el Dasein sin referencia a otros entes, a un mundo o a un "ser de los entes", que ahora se afirman como una condición de sentido de su propia constitución interna, aunque su conocimiento efectivo esté plagado de dificultades. De ahí que ahora se haga absolutamente necesario tener que situar al conjunto de objetos a los que se remite el Dasein en el horizonte interpretativo de un mundo entorno circundante, sin temor a seguir adoptando excesivas cautelas por el simple hecho de otorgar a estos principios el alcance ontológico que verdaderamente les corresponde. Las dificultades no provienen a este respecto de la inevitable formulación de la pregunta, sino de la seguridad tan pretenciosa con que aparentemente se formula. ${ }^{16}$

${ }^{15}$ KIм, H. Y., Sorge und Geschichte. Phänomenologische Untersuchung im Anschluss an Heidegger, Berlin: Duncker und Humblot, 2015.

${ }^{16}$ Messinese, L., Heideggers Kritik der abenlándischen Logik und Metaphysik. Ein kritischer Dialog, Berlin: Duncker und Humblot, 2015. 
Es más, en el caso de rechazar esta misma posibilidad de concebir un "mundo entorno", tampoco se acabaría de comprender la amplitud de horizontes que ahora genera el problema de la "vida", así como el de la "muerte"; es decir, se acabaría produciendo una mutilación innecesaria y contraproducente del peculiar proceso heurístico que a su vez genera una comprensión relacional hermenéutica ilimitadamente abierta respecto del "ser de los entes". Máxime cuando habitualmente se intenta afrontar con excesivas cautelas la fijación de todos estos posibles puntos de partida metodológicos del planteamiento inicial, prevaleciendo una actitud cautelosa, que en el fondo resulta bastante timorata. Por ejemplo, cuando se postula eludir la referencia óntica al ser mediante un recurso práctico, voluntarista y absolutamente innecesario a la ética, siendo así que este paso sólo sirve para agravar aún más los problemas óntico-ontológicos que ahora se plantean. En cualquier caso, la situación analítica originaria del Dasein consiste en esta capacidad de otorgar un doble libre sentido óntico-ontológico a la interpelación acerca del "ente", sin poder dejar de optar por una de las dos alternativas posibles al respecto. ${ }^{17}$

Heidegger otorga así al "Dasein" una comprensión relacional hermenéutica que le permite reconocer la peculiar doble dimensión óntico-ontológica de todos los entes. En este sentido formula una interpelación en toda regla a la correspondiente estructura transcendental intelectiva donde el propio Dasein se inserta. En este contexto, el Dasein constata cómo él mismo forma parte de una estructura transcendental entitativa y a la vez intelectiva donde a su vez también se fundamenta la verdad óntico-ontológica de la propia noción de "ente". Máxime cuando ahora se genera una relación de cuidado responsable y de vigilancia benevolente respecto de cada uno de los componentes de dicha estructura. Es más, se les exige mantener una actitud de interpelación constante respecto de la doble articulación transcendental-existencial que les caracteriza, según se adopte el punto de vista del horizonte global o de cada uno de sus posibles enfoques. En cualquier caso, la pregunta por el doble libre sentido óntico-ontológico que ahora el Dasein otorga a los "entes" se hace aún más exigente y apremiante, en virtud de la actitud de cuidado responsable y de

${ }_{17}$ Por eso afirma Heidegger: "Negar, ocultar o querer superar el círculo equivale a consolidar definitivamente este desconocimiento. Los esfuerzos debieran dirigirse, más bien, a saltar de un modo originario y pleno dentro de ese 'círculo', para asegurarse desde el comienzo del análisis del Dasein, la plena visión del carácter 'circular' de éste. Se supone no demasiado, sino demasiado poco para la ontología del Dasein, cuando se 'parte' de un yo carente de mundo, para proporcionarle luego un objeto y una relación a éste, carente de fundamento ontológico. Muy corto alcance tiene la mirada cuando se problematiza 'la vida' y se toma en seguida en cuenta ocasionalmente también la muerte. El objeto queda dogmática y artificiosamente mutilado cuando uno se 'limita' primariamente a un 'sujeto teorético', para luego completarlo 'por su lado práctico' con el agregado de una 'ética'. Baste con esto para la aclaración del sentido existencial de la situación hermenéutica de una analítica originaria del 'Dasein' "' (SyT, p. 331). 
"ser deudor" benevolente, que ahora fomenta la propia estructura transcendental intelectiva y entitativa donde todos ellos se encuentran insertos. ${ }^{18}$

Pero por similares razones el "Dasein" auténtico se vuelve a contraponer a los demás entes "útiles" a la mano o bien a los "otros" Dasein anónimos que simplemente están-ahí. Se hace notar así como al Dasein siempre le quedaría la capacidad de relacionarse con el resto de los entes, al modo como el hombre anónimo inauténtico se relaciona especialmente a través de un uso mancomunado, ya sea de las esencias o del lenguaje, con los demás Dasein, aunque ya sin poder hacerse falsas ilusiones de alcanzar un posible conocimiento del "ser de los entes". Especialmente cuando se les otorga la oportunidad de asignarse una singularidad de naturaleza muy precisa, a saber: el hecho de atribuirse un conjunto de rasgos compartidos con los otros Dasein, con capacidad de configurar un "mundo" humano específico suyo, que se contrapone al "mundo" que a su vez configuran los entes útiles a la mano. Se contrapone así un mundo pragmático simplemente físico y un mundo metafísico abierto a los demás "entes" y a los demás Dasein verdaderamente humano. Se trata, además, de un mundo humano que les impide remitirse a los "otros" Dasein como si fueran "entes a la mano" o simples hombres anónimos que están-ahí. A este respecto, el primer Heidegger atribuirá al Dasein auténtico una "co-existencia" solidaria junto con todos los "otros" Dasein, en la medida que se les atribuye una existencia compartida con capacidad de establecer "también" una relación de "cuidado" responsable y de "ser deudor" benevolente respecto de los demás entes. ${ }^{19}$

En cualquier caso, la "mismidad" que el primer Heidegger atribuye al ser humano auténtico no se reduce a una simple correspondencia consigo mismo, o con su respectiva naturaleza. Se trata más bien de una "co-existencia" con los específicos "otros" Dasein de sus respectivos semejantes con los que comparte un mismo "mundo entorno". En este sentido tampoco se puede ya evitar la referencia a un "mundo humano" más compartido que a su vez debería estar regido por una relación de "cuidado" responsable y de "ser deudores" benevolentes, con la exigencia añadida de tener que ser recípro-

${ }^{18}$ A este respecto afirma Heidegger: "Ahora bien, si sólo 'hay' ser en tanto que la verdad es, y si la comprensión del ser se modifica según la índole de la verdad, entonces la verdad originaria y propia deberá garantizar la comprensión del ser del Dasein y del ser en general. La 'verdad' ontológica del análisis existencial se configura sobre la verdad existentiva originaria. [...] La más originaria y fundamental verdad existencial a que tiende -preparando, en definitiva, la pregunta por el ser- la problemática ontológico-fundamental es la apertura del sentido del ser del cuidado. Para poner al descubierto este sentido es necesario tener íntegramente a disposición el contenido estructural pleno del cuidado. [...] La articulación de la totalidad del todo estructural se ha vuelto aún más rica y así se ha hecho más apremiante la pregunta existencial por la unidad de esta totalidad" (SyT, pp. 332-333).

19 Trawny, P., Heidegger y el mito de la conspiración mundial de los judios, Barcelona: Herder, 2015. 
camente solidarios entre sí. Evidentemente, esta noción del Dasein auténtico del primer Heidegger en Ser y tiempo no se identifica con la noción clásica de persona -como sujeto individual de naturaleza racional-, aunque pretende aportar una definición metafísica más precisa, a saber: una noción de Dasein como un "ser en el mundo" con capacidad de "co-existir" con los "otros" Dasein que son recíprocamente entre sí solidarios. De este modo los distintos Dasein auténticos pueden dar lugar a un "mundo humano" con capacidad de asumir unas relaciones de "cuidado" responsable y de "ser deudores" benevolentes de un modo recíprocamente solidario entre sí. De todos modos, el último Heidegger se fue distanciando progresivamente de esta visión mancomunada del hombre autentico y la fue sustituyendo por una visión cada vez más desestructurada, como acabará sucediendo en el sujeto postmoderno. En efecto, progresivamente apreció que su descripción inicial del Dasein auténtico dejaba de tener sentido en la medida que tampoco era posible superar la diferencia óntico-ontológica que se establece entre los "entes" y el "ser de los entes". Por eso su modelo de hombre auténtico acabaría dando paso a un sujeto postmoderno desestructurado que ya no puede desarrollar por sí mismo una plena sensibilidad ni una plena racionalidad ni una voluntariedad ética o un uso del lenguaje verdaderamente independiente. Por eso el último Heidegger acabaría concibiendo al Dasein como si necesariamente tuviera que establecer respecto de los demás Dasein una simple semejanza epocal cada vez más uniformemente desestructurada, al modo como también Hegel postuló entre "un" Dasein y "otro" Dasein. En cualquier caso el primer Heidegger tampoco terminó de justificar cómo el hombre auténtico podría alcanzar una efectiva fundamentación del uso de sus diversas facultades a partir de una mejor comprensión del "ser de los entes" y de los demás Dasein, sin quedarse sólo en una comprensión hermenéutica diferente, como en principio hubiera sido de esperar. ${ }^{20}$ Pero veamos que afirma Zubiri a este respecto.

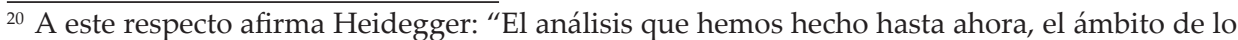
que comparece dentro del mundo, fue reducido primeramente a lo útil a la mano o bien a la naturaleza puramente presente, esto es, a entes que no tienen el carácter del Dasein. Esta limitación era necesaria no sólo para simplificar el desarrollo, sino, sobre todo, porque el modo de ser del Dasein de los otros que comparecen dentro del mundo se distingue del estar a la mano o del estar-ahí. [...] Por la caracterización del comparecer de los otros -se dirá- vuelve a tomar como punto de referencia al Dasein cada vez más propio. [... Sin embargo], 'los otros' no quiere decir todos los demás fuera de mí, y en contraste con el yo; los otros son, más bien, aquellos de quienes uno mismo no se distingue, entre los cuales también se está. Este existir también con ellos no tiene el carácter ontológico de un "co"-estar-ahí dentro del mundo. El 'con' tiene el modo de ser del Dasein; el 'también' se refiere a la igualdad del ser, común estaren-el-mundo ocupándose circunspectivamente de él. 'Con' y 'también' pueden ser entendidos existencial y no categorialmente. En virtud de este estar-en-el-mundo determinado por el 'con', el mundo es desde siempre el que yo comparto con los otros. El mundo del Dasein es un mundo en común (Mitwelt). El estar-en intramundano de éstos es la coexistencia (Mitdasein)" (SyT, pp. 138-139). 


\section{La estructura talitativa-transcendental de la personeidad en Zubiri}

Evidentemente las propuestas de Heidegger exigieron diversas prolongaciones mediante las que se pretendieron evitar las dificultades que él mismo había encontrado. A este respecto, Xavier Zubiri (1898-1983) en Sobre la esencia -SE- (1963) ${ }^{21}$ prolongó las propuestas del primer Heidegger en Ser y tiempo, aunque inicialmente siguiendo una línea que previamente Heidegger había criticado. De hecho Heidegger rechazaría esta actitud esencialista por considerarla más propia del hombre anónimo inauténtico, aunque finalmente volvería a ser retomada de un modo no deseado una vez reconocido el fracaso de su inicial proyecto programático. En este sentido Zubiri siempre mantuvo una estrecha dependencia respecto del núcleo metafísico de su proyecto programático de Heidegger. A este respecto trató de insertar a la persona o personeidad en la estructura transcendental de la intelección del ente, aunque tratase de evitar las dificultades con las que se encontró el primer Heidegger. En su opinión, se puede perfectamente justificar el anterior doble "libre sentido" otorgado al "ente" y al "ser de los entes", sin necesidad de contraponerlos entre sí, especialmente una vez que Heidegger había reconocido el fracaso de su proyecto inicial. Por eso, en su lugar, propuso una reconstrucción previa del posible doble uso talitativo y a su vez transcendental que ahora también se puede otorgar a la correspondiente noción de esencia. De hecho estableció una recíproca interacción entre ellas, con anterioridad a la mediación que también puede ejercer a este respecto ya sean lo conceptos o el propio lenguaje. En este sentido no aceptó las críticas que Heidegger había formulado a la noción de esencia por considerarla un modo de interpretación más propia del hombre anónimo inauténtico, que, en su opinión, resultaba impropia de un hombre auténtico verdaderamente comprometido con un proyecto programático de carácter metafísico. Máxime cuando ahora Zubiri pretende establecer una mutua dependencia virtuosa entre ambas dimensiones de la esencia, sin necesidad de tener que generar un círculo hermenéutico en sí mismo vicioso entre ambos aspectos del ente, como afirmaba Heidegger. En efecto, lo específico de la esencia consiste en la correspondiente apropiación de una talidad o quiddidad determinada, así como la atribución de la correspondiente función transcendental respecto de la realidad unitaria donde a su vez se inserta cada esencia junto al resto de las esencias. En cualquier caso, ya

${ }^{21}$ En el presente estudio sólo se han tenido en cuenta las propuestas de Xavier Zubiri en relación a Heidegger sobre ese sujeto relacional humano en Sobre la esencia, aunque se encuentran otros muchos lugares dedicados al tema en Inteligencia sentiente, Madrid: Alianza, 1980-1983; El hombre y Dios, Madrid: Alianza, 1984; Sobre el hombre, Madrid: Alianza, 1986; El hombre y la verdad, Madrid: Alianza, 1986; El hombre: lo real y lo irreal, Madrid: Alianza, 2005). 
no se puede prescindir de ninguno de los dos aspectos, quidditativo y transcendental, asignado a las esencias, a pesar de concebirse como dos dimensiones totalmente independientes del uso que simultáneamente se pueda hacer de los conceptos o del propio lenguaje. De hecho la intelección de ambas dimensiones de la esencia se refuerza de un modo virtuoso recíprocamente entre sí, sin necesidad de remitirse a los conceptos o al propio lenguaje, pero sin tampoco poder prescindir una de otra. Hasta el punto, que ahora la noción de esencia se caracteriza por su radical constructividad "de suyo", ya sea de un modo intrínseco respecto de sus propias notas quidditativas genéricas o de un modo transcendental extrínseco respecto del resto de las esencias. ${ }^{22}$

Zubiri hace notar cómo la apertura de toda "esencia" a un doble libre sentido talitativo y a su vez transcendental tiene la virtualidad de reforzar mutuamente este doble proceso interno de fundamentación recíproca, sin necesidad tampoco de generar un falso argumento en círculo. En efecto, Zubiri concibió la esencia como un constructo estructural entitativo que permite "de suyo" otorgar a los entes un doble libre sentido talitativo y a su vez estrictamente transcendental, sin necesidad de remitirse al lenguaje o a los propios conceptos. De hecho, que prevalezca una interpretación u otra, depende exclusivamente de que la correspondiente intelección verse acerca de sus específicas notas quidditativas genéricas o acerca de su peculiar naturaleza transcendental o estructuralmente compartida en común con el resto de todas las demás esencias, sin tampoco entrar en mayores matices. Justo por ello, Zubiri no comparte que en estos casos se genere una argumentación en círculo en sí misma viciosa, que conlleve inevitablemente el ejercicio de una violencia innecesaria contra la naturaleza de las cosas. Más bien, opina que el ejercicio de este tipo de operaciones intelectivas corresponde a una esencia abierta que, como ahora sucede con la personeidad, está verdaderamente capacitada para captar el doble sentido talitativo genérico y a la vez transcendental que se asigna al conjunto de las esencias, incluida la propia esencia abierta. Sólo en la medida que la personeidad se concibe a sí misma como una esencia abierta, también es capaz de articular este doble sentido talitativo genérico y a la vez transcendental específico que se atribuye a la globalidad de las esencias en común, pudiendo dar un paso más, a saber: justificar el mutuo reforzamiento fundamentador

${ }^{22}$ A este respecto afirma Zubiri: "Por su propia talidad, la esencia tiene una función transcendental: es aquello según lo cual la cosa es una realidad sin más, esto es, aquello según lo cual la cosa es 'de suyo'. Este 'de suyo' tiene una índole sumamente precisa, determinada por la constructividad en función transcendental. [...] La función transcendental de la talidad puede ser mucho más vasta que el mero determinar 'de suyo'. [...] No hay más realidad esenciada que la cosa en su intrínseca constructividad. Y es este constructor transcendental el que confiere realidad a todas y cada una de las notas. De ahí la distinción fundamental entre la función talitativa y la función transcendental. Y esto es verdad, no sólo por lo que se refiere a las notas, sino por lo que se refiere a la unidad misma. [...]. Pero (la esencia) sólo es en su aspecto transcendental" (SE, pp. 475-476). 
que ahora se establece de un modo virtuoso entre el respectivo ser real global y el respectivo "de suyo" quidditativo existencial simplemente genérico. ¿Qué es entonces este "de suyo"? Para Zubiri el "de suyo" se identifica con la constructividad entera del respectivo doble libre sentido talitativo genérico y a su vez transcendental específico asignado a la esencia en cuanto tal. Evidentemente el tipo de constructividad dependerá según sean esencias cerradas o abiertas. Sin embargo, en ningún caso habrá necesidad de fomentar una argumentación en círculo mediante la imposición de un tipo específico preconcebido de esencia. De todos modos la peculiaridad de la personeidad estribaría en su caso en que esa doble constructividad debería ejercerse de suyo por sí misma, tanto respecto de las esencia cerradas como abiertas, con independencia no sólo de los conceptos sino también del lenguaje. ${ }^{23}$

En cualquier caso, Zubiri reconoce la mediación que la personeidad ejerce en la configuración de la propia estructura transcendental entitativa. De este modo se concibe la persona como un principio relacional intelectivo que establece una doble correlación mancomunada entre dos dimensiones de las esencias, a saber: el aspecto talitativo y transcendental que a su vez se asigna a las notas quidditativas genéricas y a los rasgos comunes compartidos respeto de la configuración global de las esencias, tanto cerradas como abiertas. De todos modos estos dos aspectos ya no se pueden contraponer innecesariamente entre sí, como pretendió Heidegger, cuando más bien se necesitan mutuamente. De hecho Heidegger concibió la separación entre la dimensión óntica y ontológica de los entes como un presupuesto necesario para el efectivo reconocimiento de la específica condición existencial tan desesperada donde se encuentra el hombre auténtico al comprobar que no puede optar por ninguna de ambas. Sin embargo, Zubiri opina que la referencia mancomunada del aspecto quidditativo respecto del transcendental constituye el mejor modo de fundamentar la correlación recíproca que ahora se debe establecer entre las esencias cerradas y abiertas, sin necesidad de establecer una contraposición entre ellas. Se genera así un doble sentido estructural que "de suyo" se asigna a las esencias en general, con anterioridad al posible papel estructural que también puede desempeñar el lenguaje o aún más los conceptos a este respecto. Con la única diferencia que las esencias abiertas generan un doble libre sentido que requiere la colaboración del propio intelecto o de la así llamada personeidad. Se genera así una doble libre constructividad respecto de la función talitativa y transcendental de las respectivas esencias cerradas y abiertas, con una diferencia muy precisa respecto de Heidegger. Para Zubiri lo específicamente "suyo" de cada esencia en general lo constituyen priorita-

${ }^{23}$ Gómez-Heras, L. M. Ga'; Martín Gómez, M. (Eds.), Comprender e interpretar. La recepción de la filosofía hermenéutica en la España democrática (1960-2010), Salamanca: Instituto Humanidades-Universidad Rey Juan Carlos, 2015. 
riamente las notas quidditativas genéricas que se le asignan de un modo indiferenciado a cada esencia, aunque secundariamente también puedan ejercer una función transcendental subsidiaria. Hasta el punto que si las esencias no pudieran ejercer la función talitativa tampoco se podría ejercer una función transcendental, siendo la primera una condición sine qua non para ejercer la segunda. Se justifica así la atribución de unas notas comunes transcendentales a las esencias en general, como pueden ser la verdad, la unidad o la bondad. Sin embargo, estas notas transcendentales mantienen siempre una dependencia respecto de unas notas quidditativas genéricas previas que constituyen su condición de sentido. A este respecto, aquellas propiedades transcendentales se conciben como unos rasgos estructurales derivados de aquellas otras relacionales talitativas genéricas que se consideran prioritarias. Por ello, a la esencia en general, junto a una determinada quiddidad genérica existencial, también se le atribuye "de suyo" una segunda constructividad transcendental que configura de un modo mancomunado la realidad en cuanto tal. Por su parte, dentro de esta segunda constructividad más general, se incluye una segunda constructividad mancomunada más específica a la que ahora se le denomina "el mundo". ${ }^{24}$

En cualquier caso ahora se asigna a la esencia un doble libre sentido estructural, el sentido talitativo y el transcendental. A su vez ambos sentidos tienen un carácter constitutivo mancomunado, que está estructuralmente correlacionado, de modo que no se puede afirmar uno sin presuponer el otro. En efecto, en virtud de su función talitativa genérica, se predican de la esencia un conjunto de notas mutuamente compartidas; pero a su vez, en virtud de su función transcendental, todas las posibles esencias constituyen una unidad, sin poderse concebir una dimensión entitativa separada de la otra correspondiente. A este respecto, las notas de cada quiddidad permiten a su vez confirmar la unidad mancomunada existente en todo el conjunto de las esencias. Pero de igual modo la unidad transcendental asignada a todas las quiddidades de un modo mancomunado exige que las respectivas notas específicas de cada esencia se distribuyan armónicamente, sin poderlas ya modificar de un modo arbitrario. La totalidad o globalidad de las esencias configura así una noción mancomunada de realidad que "de suyo" se corresponde con la respectiva dimensión existencial de cada quiddidad concebida en general. Este desdoblamiento entre la existencia y la realidad se opera en virtud del doble

${ }^{24}$ A este respecto afirma Zubiri: “El orden transcendental está determinado por el orden de la talidad (de la esencia) en función transcendental. Pero lo que esta función determina no sólo son las propiedades transcendentales, sino una verdadera estructura transcendental. Hemos visto, en efecto, que la talidad es algo constructor, y que lo que trascendentalmente determina es el de 'suyo' como un 'constructo de realidad'. Lo real, el de suyo, es constructividad y, precisamente por serlo, este constructor se haya interna y trascendentalmente estructurado. [...] Pero era la estructura de realidad en esa respectividad transcendental que se llama mundo". (SE, p. 481). 
libre sentido talitativo y transcendental que el respectivo principio relacional intelectivo asigna a cada ente, con anterioridad al uso del lenguaje o de los propios conceptos. Surge así una noción mancomunada de realidad contrapuesta a la noción distributiva de existencia. Por su parte la existencia se configura en razón de las diversas virtualidades quidditativas y transcendentales que ahora se asignan distributivamente a cada esencia, sin necesidad de remitirse a un principio más específico que a su vez justifique el respectivo acto de ser asignado a cada ente. ${ }^{25}$

Se configura así una doble estructura entitativa -la existencial y la propiamente real-, que surge de las virtualidades quidditativas genéricas y a la vez transcendentales que se atribuyen "de suyo" de un modo distributivo a cada esencia respecto de las demás esencias. Se genera así un doble proceso de "autoplasmación", donde se pone de manifiesto la radical que caracteriza a las esencias, tanto respecto de sí mismas como respecto de las demás esencias, sin poder prescindir ya de ninguno de ambos aspectos estructurales del proceso. A este respecto toda esencia hace "de suyo" una doble referencia mancomunada intrínseca y extrínseca, a saber: por un lado, una referencia intrínseca a las notas que le especifican genéricamente como tal esencia; $y$, por otro lado, una referencia extrínseca a aquella estrecha unidad estructural que a su vez mantiene con el resto de las demás esencias y con sus correspondientes notas. A este respecto todo el conjunto de las esencias, ya sean cerradas o abiertas, mantienen una profunda coherencia interna y externa, primaria y secundaria, auto y hetero-plasmada, respecto de sus notas específicas y respecto del conjunto de todas ellas entre sí. En este sentido, el principio relacional intelectivo otorga una doble dimensión o doble libre sentido a cada esencia, según se conciba en las relaciones internas que mantiene respecto de sí misma o en las relaciones de exterioridad ("ex") que a su vez mantiene respecto del resto de las esencias. Precisamente esta doble dimensión interna y externa que articula "de suyo" a cada esencia, constituye la estructura transcendental de lo real en cuanto real. Hasta el punto que ahora también se le exige a cada esencia mantener una doble correlación de coherencia veritativa recíproca responsable y de exteriorización difusiva benéfica, sin poder prescindir de ninguna de ellas. Se asigna así a la esencia "de suyo" una radical verdad y bondad que a su vez resultan de su propia capacidad de "auto/hetero plasmación" constructiva, sin

\footnotetext{
${ }^{25}$ Señala Zubiri: "Naturalmente, recordémoslo una vez más, tratamos no de la esencia quidditativa, sino de la esencia constitutiva. La esencia tiene dos momentos: las notas esenciales y su unidad. Estos dos momentos se pertenecen intrínsecamente. Las notas califican la unidad, y la unidad está presente 'en' las notas haciendo de ellas 'notas-de' (unidad coherencial primaria): es la constructividad intrínseca de la esencia. En función transcendental, esta pertenencia constituye la realidad, el 'de suyo': es el contracto metafísico. [...] Pues bien, por ser constructa, la unidad transcendental tiene un preciso carácter estructural" (SE, pp. 482-483). ZUBIRI, X., En torno al problema de Dios, Madrid: Encuentro, 2016.
} 
necesidad de remitirse al lenguaje, a los conceptos o a cualquier otro principio ajeno a ella misma. ${ }^{26}$

Puede parecer que Zubiri asigna a cada esencia particular una constructividad "autoplasmada" que se basta por sí misma para poderse llevar a cabo. Sin embargo, convendría hacer una matización a este respecto. Se denominan esencias cerradas las que tienen una capacidad mancomunada de autorregulación "de suyo" de su propia constructividad interna y externa. De hecho, las esencias cerradas no tienen ninguna necesidad de remitirse a un principio relacional intelectivo externo que pretenda autorregularlas desde fuera de sí mismas, como ocurriría en el caso del lenguaje o de los propios conceptos. De hecho, el "mundo" se habría podido configurar por sí solo, sin necesidad de remitirse a un principio intelectivo humano. En efecto, según Zubiri, la esencia tampoco necesita hacer referencia a ningún principio relacional intelectivo que pretenda regular la estructura de lo real en cuanto tal, en su doble dimensión veritativa y a su vez benefactora de su respectiva entidad. Se trata, en cualquier caso, de una consecuencia de la doble constructividad "auto/hetero-plasmada" que ahora se asigna a las esencias en general desde el punto de vista de la verdad y del correspondiente bien, tanto en el caso de las esencias cerradas como en el de las abiertas. Sin embargo, la esencia intelectiva abierta aporta "de suyo" un conjunto de propiedades sobrevenidas respecto de lo real en cuando tal, que nunca podrían haber llegado a constituirse sin la referencia a un principio relacional intelectivo de similar naturaleza. A este respecto el reconocimiento de la estructura transcendental existente entre las esencias cerradas requiere de una colaboración mancomunada por parte de las demás esencias abiertas, con independencia del uso que en cada caso se haga a través del lenguaje o de los propios conceptos. En este sentido, la realidad global concebida por la unión mancomunada de las esencias cerradas y abiertas se configura más bien como una realidad auto-hetero-plasmada, o plasmada de forma personal y a su vez compartida. Es decir, un tipo de plasmación que requiere el concurso externo de las demás inteligencias o esencias abiertas, sin ser tampoco el resultado de una simple auto-plasmación, como sucedería si su configuración sólo dependiera de las esencias cerradas. ${ }^{27}$

En este sentido, a las esencias en general se les atribuye una capacidad de "autoplasmación" constructiva "de suyo". En cambio, a las esencias intelec-

${ }^{26}$ Zubiri advierte: "La esencia, lo real, es algo, si se me permite la expresión, "autoplasmado". La constructividad transcendental es una estructura intrínseca de interioridad y de exterioridad. Lo interior se halla actualizado en exterioridad; y, recíprocamente, lo exterior no sería exterior sino siendo el $e x$ de la propia interioridad. [...] Pues bien, el respecto formal según el cual la interioridad está plasmada en exterioridad propia, es decir, el respecto mismo del ex, es lo que constituye lo que llamo "dimensión" (SE, pp. 493-494).

${ }^{27}$ MageEe, B., Ultimate Questions, Princeton: Princeton University Press, 2016. 
tivas o esencias abiertas, además de una "autoplasmación" personal, se les asigna una hetero-plasmación o plasmación compartida junto al resto de las esencias abiertas. De este modo se configura una realidad global que abarca a todas las esencias, tanto cerradas como abiertas, y que requiere el concurso recíproco mancomunado de las demás inteligencias. $Y$ en este sentido, la plasmación mancomunada de la realidad compartida llevada a cabo por las esencias abiertas añaden una doble capacidad: 1) ser las únicas capaces de reconocer la estructura transcendental veritativa y mutuamente benéfica existente entre las diferentes esencias, ya sean cerradas o abiertas; y, por otro lado, 2) hacer posible la apertura recíproca a la respectiva estructura transcendental con la pretensión de lograr la doble "plasmación" constructiva, tanto personal como mancomunada, de la realidad en cuanto tal, cosa que las esencia cerradas nunca hubieran podido lograr por sí solas. Por eso el concepto de cerrado y abierto adquiere en Zubiri un segundo carácter transcendental muy preciso. ${ }^{28}$

Se distinguen a este respecto dos tipos de apertura mancomunada del principio intelectivo relacional: por un lado, la apertura a un nivel talitativo de una esencia intelectiva que "de suyo" se relaciona mancomunadamente con las demás esencias. Se configura así una noción de existencia que se atribuye mancomunadamente a cada una de las esencias abiertas, por el simple hecho de asignarse una quiddidad específica con la pretensión de afirmar su respectiva inserción en la verdad y al bien. Y, por otro lado, una segunda apertura transcendental más específica, que se atribuye a toda esencia intelectiva abierta con capacidad de autoafirmarse junto al conjunto de todas las demás esencias, ya sean cerradas o abiertas. Se configura así una noción de realidad global que resulta de la "auto/hetero plasmación" constructiva de todas las esencias, ya se afirmen de una forma interna o externa. En efecto, en la misma medida que una esencia abierta intelectiva también forma parte de la anterior estructura transcendental entitativa, no sólo se afirma como un elemento constituyente esencial con capacidad específica de reconocer su respectiva verdad y bondad, sino que además se asigna a sí misma la capacidad de reconocer la radical constructividad "auto/hetero plasmada", personal y a la vez mancomunada, inherente a la realidad en cuanto tal. ${ }^{29}$

De todos modos, se establece un orden de prioridades en el ejercicio de esta doble función relacional ahora asignada a las esencias intelectivas abiertas:

${ }^{28}$ A este respecto afirma Zubiri: "La esencia intelectiva es 'de suyo' abierta a todo lo real qua real. Las esencias cerradas son, pues, las que no son intelectivas. La inteligencia, que es una nota esencial, tiene una función transcendental exclusiva de ella. Por eso, la diferencia entre lo intelectivo y lo no intelectivo, es una diferencia transcendental y no sólo talitativa. Abierto y cerrado son dos tipicidades transcendentales" (SE, p. 501).

${ }^{29}$ Millán Puelles, Antonio, Obras completas. VII. Léxico filosófico (1984), Madrid: Asociación de Filosofía y ciencia contemporánea/Rialp, 2015. 
lo prioritario consiste en la función talitativa que permite identificar la radical verdad y bondad de una esencia en cuanto tal, así se trate de una esencia cerrada o abierta. Sin embargo, en un segundo momento, la esencia intelectiva abierta también se concibe a sí misma como un principio constituyente al que se asigna una radical constructividad "auto/hetero plasmada", personal y a la vez mancomunada. Es decir, una forma de configuración compartida que es inherente a la propia estructura transcendental entitativa, de modo que sin su concurso tampoco se le podría advertir la efectiva plenitud de la realidad global en cuanto tal. En este contexto, la personeidad no sólo se asigna una capacidad de reconocer la verdad y el bien que posee "en sí" toda esencia intelectiva abierta, por el simple hecho de ser una esencia. Pero, además, en un segundo momento, la personeidad también comprueba que su concurso se hace absolutamente necesario para reconocer la radical constructividad "auto/hetero plasmada" de la realidad global inherente al conjunto de demás esencias. ${ }^{30}$

A este respecto, las esencias intelectivas mantienen una peculiar doble apertura veritativo-benefactora respecto del resto de las esencias cerradas y abiertas. En efecto, a pesar de que el resto de las esencias cerradas no forman parte de su "ser en si", su concurso se hace absolutamente necesario para reconocer la verdad y el bien específico aportado mancomunadamente por las propias esencias cerradas al conjunto de las esencias intelectivas abiertas. Se trata de dos momentos mutuamente dependientes entre sí desde un punto de vista estructural, de modo que "de suyo" no puede darse uno sin el otro. En este sentido, la esencia intelectiva abierta no puede darse sin la referencia a las esencias cerradas, aunque perfectamente podría ocurrir y de hecho ha ocurrido durante siglos lo contrario. Precisamente, la fusión de ambas dimensiones veritativo-benefactoras configura lo real en cuanto real. Se trata de la aportación específica de la esencia intelectiva abierta a todo el conjunto de las esencias cerradas. Sólo mediante el concurso de las esencias abiertas se puede concebir el resto de las esencias cerradas como algo efectivamente verdadero y bueno, aunque su concurso no se requiera para su efectiva existencia. ${ }^{31}$

De este modo, la esencia abierta o personeidad se afirma como un principio intelectivo relacional que se sitúa a un nivel transcendental que "excede" la simple relación de mera "conveniencia" o "no conveniencia", de "coherencia" o "no coherencia", de "bondad" o "no bondad", respecto del resto de las esencias cerradas. En su lugar se establece más bien entre ellas una relación de mediación a un nivel de fundamentación transcendental. En este sentido, sin una referencia mancomunada a las respectivas esencias intelectivas tampoco

\footnotetext{
${ }^{30}$ Burgos, J. M. (Ed.), España vista por sus intelectuales, Madrid: Palabra, 2015.

31 Aguirre OraA, J. M. (Ed.), Retos y perspectivas de la filosofía para el siglo XXI, Barcelona: Anthropos, 2015.
} 
se podría identificar el carácter abierto o cerrado, hetero/auto plasmado, verdadero o falso, benefactor o perjudicial, que cada esencia mantiene a su vez respecto del resto de las esencias. ${ }^{32}$

En cualquier caso las esencias cerradas forman parte material de la estructura transcendental entitativa. Sin embargo, por sí solas, serían incapaces de lograr un efectivo reconocimiento de la función específica transcendental que desempeñan a este nivel. Sólo podrían reconocer el ejercicio de una función transcendental como la ahora descrita si se les atribuyera subsidiariamente este papel en virtud de la transcendentalidad que a este respecto sólo pueden ejercer "de suyo" unas esencias intelectivas abiertas. En efecto, sólo las esencias abiertas son capaces de reconocer la verdad y al bien que ahora se asigna a los entes en general. En este sentido, sólo las esencias intelectivas abiertas pueden concebirse como personas; es decir, como una esencia intelectiva abierta a la que se asigna una capacidad específica de reconocer la verdad y el bien derivados del conjunto de mediaciones que ejerce la globalidad del ser en general, tanto a nivel existencial como a nivel de realidad, sin poder ya permanecer encerradas en sí mismas. En cambio el ser vivo en general y los animales en especial, siguen siendo esencias cerradas que sólo son materialmente "suyas" desde un punto de vista meramente talitativo y existencial. Sin embargo, su contribución a la estructura transcendental en cuanto tal sigue siendo totalmente subsidiaria y ajena, ya que el reconocimiento de su propia condición sólo se alcanza "de suyo" a través de las esencias abiertas. En efecto, el mundo podría existir sin necesidad de las esencias abiertas, pero entonces carecería del reconocimiento que le reporta una estructura intelectiva propiamente transcendental. ${ }^{33}$

A este respecto las esencias cerradas carecen de la capacidad de reconocer la verdad y el bien que de un modo radical aporta la doble dimensión talitativa y transcendental que desempeñan, a diferencia de lo que sucede con las esen-

\footnotetext{
${ }^{32}$ Zubiri afirma: "Aclaremos algo estos conceptos. En primer lugar, la apertura no apunta primaria y formalmente al término al que se está abierto. [...] Apertura no significa la condición del término al que se está abierto, sino la estructura misma de la esencia intelectiva en cuanto algo 'de suyo'. De aquí se sigue que la esencia intelectiva tiene una función transcendental peculiar. La esencia talitativamente intelectiva en función transcendental instaura esa esencia ante todo como algo real, como algo que 'de suyo' es algo 'en sí'; pero a una con ello, la instaura como algo trascendentalmente abierto a lo que ella -la esencia intelectiva- no es en sí, o a su propio ser en sí. Estos dos momentos no son estructuralmente independientes, y en su mutua pertenencia transcendental consiste formalmente el tipo de constructor metafísico a que estamos aludiendo. En esto se funda la "conveniencia" con todo lo real qua real, y por consiguiente el verum y el bonum. Por esta conveniencia la función transcendental de la inteligencia excede a la mera instauración como realidad propia. Pero este 'exceder', es decir, la 'conveniencia' no es algo primario, sino que es la consecuencia de una estructura transcendental de la esencia intelectiva: la apertura transcendental" (SE, pp. 501-502).

${ }^{33}$ Lacalle Noriega, M., La persona como sujeto de derecho, Madrid: Dykinson, 2016, $2^{\underline{a}}$ ed. [1 $1^{\underline{a}}$ ed., 2013].
} 
DASEIN, PERSONEIDAD, INTERSUBJETIVIDAD Y PERSONA-NÚCLEO (II).

La estructura trascendental intelectiva después de Heidegger, en Zubiri, Apel y Polo

cias intelectivas abiertas. En este sentido, las esencias intelectivas abiertas se afirman como si fueran reduplicativamente reales. Primero, en cuanto reconocen la verdad y el bien de su específico carácter talitativo intelectual abierto. Y en segundo lugar, debido a su contribución a la "auto/hetero plasmación" de la específica realidad constructiva global, tanto a nivel personal como mancomunado. En cualquier caso, a la globalidad de los entes se les asigna "de suyo" la configuración de una estructura transcendental que abarca a todas las esencias, ya sean cerradas o abiertas. Las esencias intelectivas abiertas aportan así un sentido de la realidad por partida doble. Por un lado, en cuanto ellas mismas reconocen la verdad y la bondad que les corresponde a su propia realidad específica como tales esencias abiertas. Por otro lado, en cuanto son las únicas capaces de advertir la afectiva realidad constructiva global que configura de un modo mancomunado el conjunto de todas las esencias. Precisamente este carácter reduplicativo hace que la inteligencia no sea sólo una realidad como las demás, sino que se reconozca como el referente obligado de la estructura transcendental entitativa que a su vez configura la realidad en cuanto tal. Por eso el ser humano se constituye como una persona, o más bien, como una personeidad, como ahora se prefiere denominar. ${ }^{34}$

De todos modos la inteligencia sola no constituye a la persona o personeidad, aunque sin inteligencia tampoco puede hablarse de un ser personal. Por tener inteligencia se asigna a la personeidad humana una apertura mancomunada a todo lo real en cuanto tal, sin que en principio haya que ponerle ninguna limitación a esta singularidad propia suya. De todos modos lo propio de la intelección humana no es una comprensión hermenéutica de sus respectivos objetos, al modo postulado por Heidegger. Lo propio suyo es más bien una intelección discursiva mancomunada a partir de la información sensible procedente de la experiencia. Hasta el punto que para Zubiri ya no pueden disociarse la intelección respecto de la sensación, sino que ambas dimensiones discursivas están estructuralmente unidas en el respectivo proceso mancomunado de conocimiento. De ahí que la inteligencia sea sentiente en la medida que la impresión es un constitutivo inherente a la propia intelección, sin que pueda haber una intelección sin remitirse a la respectiva impresión sensible. Ello no impide que

${ }^{34}$ Afirma Zubiri: “La esencia cerrada es, por así decirlo, sólo 'materialmente' suya. [...] Estas diferencias (entre las esencias cerradas) no son propiamente transcendentales sino más bien talitativas. Trascendentalmente el ser vivo se pertenece así mismo sólo "materialmente"; trascendentalmente es esencia "cerrada". [...] Por eso el animal no tiene sino individualidad; es "suyo" pero tan sólo "materialmente", esto es, sólo como individuo transcendental. La esencia estrictamente abierta es suya "formal y reduplicativamente", como he solido decir; no sólo se pertenece a sí misma, sino que tiene ese peculiar modo de pertenecerse que es poseerse en su propio y formal carácter de realidad, en su propio "ser suyo". Es su realidad en cuanto tal la que es "suya". [...] Tomado este poseerse como un carácter del acto primero, este modo de ser suyo es justo lo que constituye la persona" (SE, p. 504). 
la inteligencia se remita de un modo mancomunado a lo real en cuanto tal, pero siempre a través del correspondiente correlato sensible. ${ }^{35}$

En este sentido, la intelección humana ahora se concibe como un componente sobreañadido a la animalidad, en cuanto que la posesión de un conocimiento sensible constituye un componente específico inherente de los niveles vitales más inferiores. En cualquier caso, lo característico de la persona humana consistiría en la asignación de un determinado nivel de animalidad, pudiéndose definir la persona o personeidad humana como un animal de realidades, o incluso como un simple animal personal. Es decir, la personeidad sólo añadiría una capacidad de abrirse paso hacía lo real en cuanto tal, en la medida que la inteligencia sigue manteniendo una dependencia mancomunada respecto de la realidad sensible. Sin embargo, la personeidad no podría elevarse a otras manifestaciones vitales más superiores que pudieran exigir un progresivo desprendimiento o alejamiento de lo sensible. Por eso tampoco pudo admitir una efectiva apertura de la racionalidad, de la voluntad, de la propia ética o del uso compartido del lenguaje, respecto de un uso verdaderamente transcendental de las esencias, como en principio se había postulado en su proyecto inicial. En cualquier caso las propuestas de Zubiri tendrían un coste evidente: la imposible asignación a dicha personeidad de una mejor fundamentación mancomunada respecto del alcance verdaderamente transcendental otorgado especialmente a la personeidad abierta, y no simplemente de un modo diferente respecto de algunas quiddidades cerradas más o menos útiles. ${ }^{36}$ Pero pasemos a ver qué afirma a este respecto Apel.

\section{La estructura pragmático-transcendental del co-sujeto comunicativo en Apel}

Las propuestas de Heidegger también fueron compartidas y prolongadas por Karl-Otto Apel (1922) en Transformación de la filosofía-TF- (1963-1973). En este sentido Apel siempre mantuvo una dependencia respecto del proyecto

\footnotetext{
${ }^{35}$ Snowdon, P. F., Persons, Animals, Ourselves, Oxford: Oxford University Press, 2014.

${ }^{36}$ A este respecto afirma Zubiri: “Toda inteligencia es apertura a lo real qua real. [...] Pues bien, lo que constituye la apertura de esta esencia intelectiva que es el hombre, no es primariamente la comprensión, sino el hallarse vertida desde sí misma, en tanto que inteligencia, al sentir; esto es apertura a la impresión. [...] De suerte que inteligencia y sentir forman una sola estructura, la inteligencia sentiente, gracias a la cual toda la realidad es sentida en impresión de realidad [...]. Puede darse, y de hecho se da, sentir sin intelección, pero la recíproca no es cierta: toda intelección es últimamente sentiente. Por eso el hombre 'es animal de realidades'; y de ello resulta que el hombre es un 'animal personal'. El hombre va elaborando su personalidad en distensión y en protensión precisamente porque estructuralmente es ya personeidad, y lo es animalmente" (SE, p. 507).
} 
programático inicial de Heidegger, aunque denunciara numerosas desviaciones que él mismo en su última época fue introduciendo. De hecho el primer Heidegger también rechazaría esta actitud semiótica por considerarla más propia del hombre anónimo inauténtico, aunque al final fuera el único modo factible al que se vería obligado a recurrir en la situación tan desesperada donde él mismo se acabó instalando. En cualquier caso Apel y Heidegger acabaron compartiendo la necesaria mediación de un co-sujeto semiótico compartido en la peculiar estructura transcendental hermenéutica, que a su vez hace posible la comprensión del "ser de los entes", aunque con una diferencia: en ningún caso Apel considera el recurso al lenguaje como una actitud más propia del hombre anónimo inauténtico, cuando de hecho sin referencia al lenguaje tampoco se puede iniciar un proceso de comprensión recíproca, ya sea respecto de los entes o respecto a los demás Dasein. De todos modos desde un inicio Apel discrepa respecto del dramatismo y la vehemencia progresiva con que Heidegger describió la diferencia óntico-ontológica que en su caso había establecido entre cada "ente" en particular y el "ser de los entes" en general. Al principio, Heidegger la concibió como una diferencia fundamental que permite separar el esencialismo del hombre anónimo inauténtico respecto del dramatismo existencial con que el hombre auténtico debe afrontar su respectivo "ser en el mundo". Sin embargo, Heidegger la terminó considerando una diferencia intransitable, por más ilusiones que el hombre auténtico se haga en sentido contrario considerando que se puede rebasar. Justo por ello, Heidegger se vería obligado a reconocer la mediación que las esencias y el correspondiente lenguaje ejercen a la hora de concebir los "ente". Por su parte Apel tratará de desactivar desde un principio este dramatismo existencial con que el primer Heidegger concibió este tipo de mediaciones, y que la acabaría desembocando en un derrotismo metafísico en toda regla. Para lograrlo, trató de mostrar con ayuda de la hermenéutica el posible carácter virtuoso en vez de vicioso del círculo interpretativo que se establece entre esta doble dimensión óntico-ontológica que en Heidegger presentan los entes. En su lugar se pretende así mostrar cómo se trata de un simple paso semiótico perfectamente transitable entre dos extremos opuestos mutuamente compatibles, a saber: por un lado, las interpretaciones meramente interesadas que se darían por parte de los afectados ante la presencia de un determinado "ente" o acontecimiento simplemente útil; $\mathrm{y}$, por otro lado, la formulación de un consenso interpretativo desinteresado y verdaderamente compartido por todos los afectados, sin imposiciones por ninguno de los participantes en el dicho discurso, acerca del significado efectivo otorgado a dicho "ente" o acontecimiento. Sólo así sería posible seguir interpretando la diferencia óntico-ontológica de Heidegger como la ejecución hermenéutica de un doble proceso de comprensión semiótica, a saber: por un lado, el proceso hermenéutico que permitió anteriormente resaltar la denominada dimensión óntica de los respecti- 
vos entes o acontecimiento; es decir, la capacidad de concebir esos mismos entes o acontecimientos de un modo pragmático como meros entes a la mano respecto del valor meramente utilitario que pueden tener para el hipotético co-sujeto o interlocutor en cada caso interpelado; $y$, por otro lado, el proceso hermenéutico que permitió seguir resaltando la anterior segunda dimensión estrictamente ontológica de esos mismos entes o acontecimientos; es decir, la capacidad de otorgar a estos mismos "entes" o acontecimientos un alcance verdaderamente transcendental, o más bien pragmático-transcendental, como término de un "consensus omnium" que podría acabar afectando por igual al conjunto de todos los potenciales co-sujetos interpelados por el planteamiento de un determinado problema. ${ }^{37}$

Pero a pesar de este acuerdo con el planteamiento inicial, Apel discrepó abiertamente con Heidegger en dos extremos. Primero respecto de la necesidad de radicalizar progresivamente la diferencia óntico-ontológica, cuando se sabe de antemano que no hay procedimiento heurístico que permita transitarla en condiciones de normalidad. Al menos así habría acabado sucediendo en el último Heidegger, cada vez con más vehemencia y dramatismo, cuando en su programa inicial no estaba previsto un cambio de orientación de este tipo. Pero, en segundo lugar, Apel tampoco comparte la atribución al lenguaje del círculo hermenéutico en sí mismo vicioso que Heidegger estableció entre los respectivos enfoques semióticos de ambos procesos. A su modo de ver, el lenguaje podría perfectamente haber sido parte de la solución, en vez de constituir el núcleo del problema. Máxime cuando se comprueba que el lenguaje ejerce una doble mediación que podría acabar desactivando el carácter vicioso que Heidegger atribuyó al doble proceso de comprensión óntico-ontológico, que en su caso estableció entre los entes y el "ser de los entes". Primero por tratarse de una mediación necesaria, dado que sin lenguaje tampoco el Dasein podría interpelar a los entes en la forma como Heidegger propuso. Segundo, por permitir reinterpretar la diferencia óntico-ontológica en un sentido pragmático-transcendental que transforma en virtuoso el círculo hermenéutico anteriormente considerado vicioso. Se pretende desactivar así una dificultad que Heidegger consideraba insuperable. ${ }^{38}$

Además, Apel opina a este respecto que las propuestas de Heidegger reeditaron la peculiar estructura transcendental hermenéutica que anteriormente había propuesto el historicismo vitalista de Dilthey. En este sentido tanto Dilthey como Heidegger habrían afrontado desde un punto de vista pragmático,

${ }^{37}$ Galluzo, G.; Loux, M. J., The Problems of Universal in Contemporary Philosophy, Cambridge: Cambridge University Press, 2015.

${ }^{38}$ Maddalena, G., The Philosophy of Gesture. Completing 'Pragmatists' Incomplete Revolution, Montreal: McGill-Queen's University Press, 2015. 
tanto el problema de la vida, como sus vivencias y expresiones a través del correspondiente ser histórico, sin necesidad de remitirse a un inalcanzable "ser de los entes". Con la ventaja añadida de que Heidegger habría sustituido la vida por una previa comprensión de un ser-ahí desde un "ser-para" utilitario de carácter simplemente pragmático, a pesar de haber seguido perpetuando a este respecto el error inicial de Dilthey de tampoco haberse elevado a un plano verdaderamente pragmático-transcendental, como hubiera sido de desear. En cualquier caso tanto Dilthey como Heidegger se habrían remitido implícitamente a una finalidad común previamente consensuada de un modo pragmático-transcendental, al modo como ahora también exige Apel, siguiendo a Peirce. En este sentido ambos habrían postulado una estructura transcendental hermenéutica del comprender que pretende compensar desde un principio estas carencias de las propuestas de Dilthey o Peirce, a pesar de que Heidegger nunca lo habría formulado explícitamente. De este modo se pretende concebir el ser-ahí de Heidegger cómo un sustituto pragmático de la vida y del respectivo ser histórico, a pesar de que Heidegger consideró este tipo de propuestas como más propias del hombre anónimo o inauténtico. De todos modos se justifican así las propuestas que el primer Heidegger acabó formulando de un modo no explícito o pre-ontológico desde un horizonte de comprensión histórica cada vez más indeterminado. De hecho el primer Heidegger en Ser y tiempo se habría ido alejando progresivamente de la realidad presente, con la única pretensión de marcase un horizonte donde tuvieran cabida la totalidad de las vivencias correspondientes a los respectivos Dasein o simples "seres-ahí". Por eso sus propuestas iniciales acabaron volviéndose cada vez más distante y abstractas, como ahora sucede con la pretensión de abarcar a un inaccesible "ser de los entes", cuando se debería haber conformado más bien con abarcar a la "vida" y a la realidad histórica en todas sus manifestaciones. ${ }^{39}$

Heidegger habría llegado así en Ser y Tiempo a una solución de compromiso similar a la que también habría propuesto en su última época Dilthey o el primer Peirce, con una única diferencia, a saber: en su caso, el último Dilthey y el primer Peirce habrían pretendido neutralizar la aparición del anterior círculo hermenéutico vicioso de la comprensión hermenéutica mediante la aparición de otro círculo de carácter virtuoso, donde se pudieran tener en cuenta de un modo simplemente sobreentendido los intereses de los demás afectados. Además, el último Dilthey y el primer Peirce habrían pretendido sustituir el recurso a un principio de supervivencia individual meramente utilitario o pragmático por otro todavía más abierto que pudiera estar semióticamente mejor compartido de un modo pragmático-transcendental, a fin de

${ }^{39}$ Наdot, P., El velo de Isis. Ensayo sobre la historia de la idea de la naturaleza, Barcelona: Alpha Decay, 2015. 
tener en cuenta de un modo consensuado la totalidad de los intereses puestos en juego por los distintos agentes afectados en este tipo de procesos. ${ }^{40}$

En cualquier caso, Apel considera que el primer Heidegger sustituyó la pregunta por vida y, en definitiva, por el ser, para poner en su lugar la pregunta por el posible sentido otorgado en cada caso ya sea a la vida o al ser, hasta el punto que el "Dasein" habría pasado a desempeñar el papel de un principio comprensivo relacional similar al que en la filosofía clásica habría sido desempeñado de un modo no explícito por una efectiva intelección del propio ser. Todo dependería de que el Dasein quisiera asignar a los "entes" un sentido utilitario más o menos abierto a los intereses de los demás afectados, dejando abierta incluso la posibilidad de un "consensus omnium" entre todos ellos, al modo postulado por el primer Peirce. Especialmente, si se tiene en cuenta que en ese caso el ser también se trata de una noción que abarca en sí intencionalmente a todos los posibles interlocutores afectados por un hipotético discurso, tanto los efectivos como los meramente posibles o hipotéticos. En cualquier caso, la universalidad y la transcendentalidad que la filosofía tradicional atribuía a las nociones ya superadas de intelección del ente, de la verdad y del bien, acabarían siendo sustituidas ahora por la noción hermenéutico-filosófica de la comprensión de la vida y de su correspondiente ser histórico, al modo del último Dilthey. O bien, por las nociones pragmático-transcendentales de consenso o de acuerdo racional definitivo, al modo del primer Peirce. A este respecto, según Apel, Heidegger también habría concebido el ser como un receptáculo abarcador igualmente universal y transcendental, donde tiene lugar todo posible acontecer respecto del doble proceso de comprensión de que puede ser objeto de un modo compartido todo ser, la vida o el ser histórico en general. O donde puede tener cabida un doble proceso pragmático-transcendental de puesta de acuerdo en común, donde se pudiera alcanzar un consenso verdaderamente racional. De hecho el tránsito de una interpretación a otra se llevaría a cabo según se estableciese como prioritaria una relación de utilidad pragmática que de un modo particular cada Dasein se otorga a sí mismo; o bien, por el contrario, si se otorga una prioridad a un virtual consenso universal respecto del valor de la hipotética utilidad mancomunada que de un

\footnotetext{
${ }^{40}$ A este respecto afirma Apel: "En su hermenéutica existenciaria, Heidegger reemplaza la vida -que se comprende dentro del círculo hermenéutico de vivencia y su correspondiente expresión- por el 'ser-ahí' humano, en el cual el ser en general ha accedido a una relación de comprensión consigo mismo. Este enfoque le permite repetir la pregunta platónico-aristotélica por el ser del ente (por el 'ontos on') como la pregunta del 'sentido del ser' presuponiendo que existe un horizonte de comprensión para dicha pregunta, a saber: el 'ser-ahí' del hombre ('Dasein') que, en su ser, 'comprende el ser-para' y, de este modo comprende al mismo tiempo y de modo no explícito (preontológico) al ser de todos los demás entes" (TF, I, 271 p.).
} 
modo general compartido está sobreentendido en estos casos, sin necesidad tampoco de tener que hacer mayores matizaciones a este respecto. ${ }^{41}$

De todos modos, según Apel, el primer Heidegger no habría terminado en Ser y Tiempo de dar una correcta solución al problema de la comprensión de la multiplicidad de sentidos que desde un punto de vista histórico-vital o pragmático-transcendental se pueden otorgar a la vida, al "ser" $\mathrm{y}$, en definitiva, a los diferentes acuerdos fácticos en los que se puede participar unilateralmente. Especialmente, debido a diversos malentendidos lingüísticos que a su vez generan una incorrecta autocomprensión del papel específico desempeñado por la propia filosofía hermenéutica en este mismo proceso. En efecto, según Apel, Heidegger introduce una radicalización hermenéutica en el modo de abordar la pregunta por los posibles sentidos utilitarios otorgados al ser, sin haber llevado a cabo una previa reflexión histórico-vial, crítico-transcendental, o más bien pragmático-transcendental, acerca de las condiciones de posibilidad y de sentido de este mismo tipo de procesos utilitarios, pragmáticos o simplemente vitales. De este modo se originan numerosos malentendidos, que fácilmente podrían haberse evitado. De hecho, Heidegger trató de abordar la pregunta por la comprensión del sentido del ser en su conjunto, o del "ser de los entes" en general, contraponiéndola a su vez con el modo habitual de alcanzar una simple comprensión utilitaria o pragmática de los distintos entes en particular. Abordó ambos problemas como si se tratara de dos cuestiones completamente distintas, cuando, según Apel, ambos procesos ya no pueden separarse. O mejor dicho, en el caso de separarse tampoco se puede evitar la aparición de un círculo hermenéutico en sí mismos vicioso, así como un proceso de autoenajenación aún mayor, donde se rechazan justamente los presupuestos que hacen posible este mismo proceso, como efectivamente acabó sucediendo en el último Heidegger. Sin embargo, este indeseado desenlace podría fácilmente haberse evitado si desde un principio se hubiera puesto de manifiesto que ambos procesos están intrínsecamente interconectados, cosa que Heidegger nunca quiso apreciar. ${ }^{42}$

${ }^{41}$ Apel señala: "Heidegger no cuidará en su pregunta por el 'sentido del ser' de que la palabra 'ser', tal y como la entienden los filósofos, tenga un sentido, sino que ese sentido se haya entendido de manera adecuada en la metafísica tradicional, y creerá que justamente los problemas suscitados por el pensamiento histórico [...] encuentran un adecuado desarrollo en el marco de una 'hermenéutica' que comprenda el ser desde la historicidad de la existencia humana. El ser no es, por tanto, en Heidegger un concepto tan extenso como abstracto -en analogía con lo universal de un género- sino que, antes bien, está pensado en analogía con la vida de Dilthey, que se interpreta a sí misma de modo biográfico o histórico-universal. Lo que diferencia a Heidegger de Hegel y Dilthey es sin duda el hecho de que la vida = el ser no es primariamente 'comprendida' ex post -como algo adquirido ya en su articulación de significatividad -sino ante todo como algo que tiene que vivirse hacia delante (Kierkegaard)" (TF, I, 279 p.).

${ }^{42}$ Por eso Apel afirma: "El propio Heidegger hizo en Ser y Tiempo una clara distinción entre la autocomprensión 'existencial' dentro de la situación, que corresponde a la 'reflexión efectiva' del lenguaje en que 'uno' se comprende, y la comprensión 'existenciaria' propia de la filoso- 
De todos modos, a pesar de estas deficiencias, Apel atribuye a Heidegger la localización de la ahora denominada estructura, o más bien la pre-estructura transcendental del comprender. En este contexto, la expresión "pre-ser-se" sólo indica la capacidad del "Dasein" de apropiarse aquellos procesos fenomenológicos y hermenéuticos que hacen posible la "constitución" de sentido. Es decir, la atribución de aquella peculiar "pre-estructura del comprender", o del particular "por mor-de" de la "cura", del cuidado responsable o del "ser deudor" benevolente, que ahora se asigna de un modo simplemente pragmático o utilitario al propio Dasein. En efecto, en todos estos casos el propio "Dasein" debe reconocer desde un principio la posición tan singular que ocupa en el "mundo" o incluso respecto del propio "ser de los entes", sin poderse considerar un simple espectador imparcial de todo lo que ocurre a su alrededor. ${ }^{43}$

Especialmente si se le sigue concibiendo como el auténtico protagonista capaz de apropiarse de las peculiares relaciones hermenéuticas, utilitarias o pragmáticas que a su vez el Dasein mantiene respecto de cada uno de los "entes" o incluso de los propios "hechos" vitales y de los correspondientes acontecimientos históricos. En efecto, ya contribuya en poco o en mucho, tampoco ya puede eludir la responsabilidad que todo este proceso genera de un modo histórico-vital y pragmático-transcendental. Quiera o no quiera, a él le corresponde hacerse responsable de la situación privilegiada de la que dispone en relación al posible "cuidado" responsable del resto de los "entes" o incluso de los "hechos" o "eventos" históricos que acaecen en un "mundo" humano compartido. Sobre él recae la responsabilidad de tratar de hacer compatibles entre sí las diversas utilidades que de un modo histórico-vital o pragmático-transcendental se puedan originar. Es decir, se debe sentir responsable de la libertad transcendental ontológica que le corresponde para dotar al "mundo entorno" que le rodea de una adecuada "constitución de sentido" y de la correspondiente "pre-estructura" del comprender, que a su vez se afirma en nombre de unos presupuestos histórico-vitales y pragmático-transcendentales muy precisos. En cualquier caso se produce en Heidegger un progresivo tránsito de poner el acento en los problemas ontológicos a este otro donde prevalecen los problemas hermenéuticos o simplemente pragmáticos. Sin embargo Apel considera que en ningún caso el planteamiento más accesible de esta segunda cuestión se debe interpretar como una renuncia al logro de aquella otra estructura transcendental hermenéutica de la autocomprensión

fía. Según Heidegger, ésta tiene que 'radicalizar' la 'comprensión preontológica del ser' que

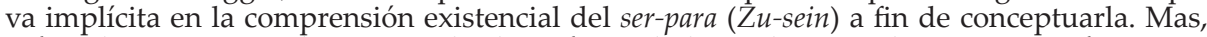
¿cómo hay que entender esta 'radicalización'? -de la inteligencia de esta expresión parece depender en Ser y Tiempo la respuesta a la pregunta por la posibilidad y validez de los enunciados filosóficos"' (TF, I, pp. 237-238).

${ }^{43}$ Curtis, W. M., Defending Rorty. Pragmatism and Liberal Virtue, Cambridge: Cambridge University Press, 2015. 
del ser antes propuesta por Heidegger, sino simplemente como un modo más adecuado de llevarla a cabo. ${ }^{44}$

Evidentemente, Apel considera que el primer Heidegger en Ser y tiempo dio un paso de gigante respecto al modo como la filosofía crítico-transcendental debería llevar a cabo una efectiva justificación pragmática de las condiciones de posibilidad y de sentido del correspondiente proceso de comprensión hermenéutica. La novedad principal estriba en que ahora los diversos Dasein o principios agentes afectados por este tipo de procesos, ya no se afirman como un sujeto transcendental extraño o autoenajenado que pudiera situarse a su vez fuera del mundo. En su lugar más bien el Dasein se convierte en uno de los principales protagonistas que entran a formar parte de la configuración histórico-vital y pragmático-transcendental de la propia estructura del comprender. En cualquier caso, el papel de este tipo de principios agentes o de los distintos Dasein ya no estriba en generar un proceso de producciones subjetivas de la conciencia pura, como Husserl habría denunciado respecto de las propuestas de tipo kantiano. En su lugar se considera más bien como Heidegger habría denunciado que estos procesos de interacción recíproca hubieran seguido manteniendo una naturaleza de carácter subjetiva. Por eso habría puesto de manifiesto como responden a una "pre-estructura 'a priori' de la comprensión" que tiene unos presupuestos histórico-vitales y pragmático-transcendentales muy precisos ${ }^{45}$

De todos modos Heidegger no prosiguió esta línea de argumentación que le habría llevado a resultados muy distintos. En efecto, Heidegger asigna a los procesos fenomenológicos de "constitución de sentido" un carácter vital, pragmático o utilitario en sí mismo objetivo, cuando de hecho siempre están abiertos a la posibilidad de alcanzar un sentido histórico, así como un posible acuerdo o consenso al respecto muy preciso. Según Heidegger, el posible sentido de cada ente "se constituyen o se han constituido ya siempre para nosotros",

${ }^{44}$ A este respecto afirma Apel: "Ya en la expresión 'pre-ser-se' queda patente, a mi juicio, que Heidegger en Ser y tiempo todavía no había roto totalmente la relación con una filosofía transcendental de la 'subjetividad' en sentido kantiano. Por ello, en Kant y el problema de la metafísica pudo conciliar todavía el 'carácter de proyección' del comprender que se transciende a sí mismo y a todo ente, con la 'espontaneidad' de una 'imaginación transcendental' en sentido kantiano. También la 'interpretación' del 'pre-ser-se' como 'cura', tal y como exige el 'por-morde-qué' del 'ser-en-el-mundo', y sobre todo el discurso sobre el ya siempre 'ser deudor' del ser-ahí, prueban que en aquel momento pudo no ser desacertado entender la 'preestructura' del comprender, al menos también, como un problema de la identidad del hombre consigo mismo, que se puede aceptar o rechazar. En ello podía haberse descubierto enteramente el problema de reconstruir, a la vez empírica y normativamente, las condiciones de posibilidad y validez de la comprensión del mundo y de sí mismo, involucradas en la 'preestructura'; problema que tiene que ser resuelto también con medios científicos" (TF, I, p. 37).

${ }^{45}$ Hösle, V., Suárez Müller, F. (Hrsg.), Idealismus Heute. Aktuelle Perspektiven und neue Impulse, Darmstatd: WBG - Wissenschaftliche Buchgesellschaft, 2015. 
sin poder ya alterar este carácter ya-dado o configurado que de un modo histórico-vital y pragmático-transcendental ahora se les asigna. Hasta el punto que lo único que cabe hacer en esta situación tan constreñida es decidir si se pone en ejercicio el efectivo "despejamiento" de todos aquellos condicionamientos que a su vez impone el llamado "a priori" lingüístico de la comprensión. Hasta el punto que en ese caso habrá que declarar como vicioso el anterior círculo hermenéutico de la comprensión que hasta entonces parecía virtuoso. Es más, para Heidegger, ahora también se debería incluir el "despejamiento" del "ahí" que a su vez constituye el peculiar modo de autodescribirse del "Dasein" a sí mismo, por considerarlo un principio que tampoco debe quedar al margen de este tipo de "despojamientos". En efecto, el Dasein necesita hacer una referencia al "ser-ahí" para poder autoasignarse una auténtica "constitución del sentido" histórico vital y pragmático-transcendental. De no hacerlo, se hubiera hecho imposible la autoasignación de un lugar frente a los demás acontecimientos vitales o frente a los "entes" en general y frente el "ser de los entes" en especial. En cambio, al describir el Dasein como un "ser-ahí", Heidegger habría establecido un procedimiento para desactivar la mediación de un "a priori" perfecto que a su vez genera un proceso de convergencia progresiva entre los distintos factores que confluyen en los respectivos procesos de comprensión recíproca. En efecto, si no mediara la referencia a un "ser ahí", tampoco se podría describir al Dasein, ni tampoco a ninguno de los "seres a la mano" que constituyen su mundo entorno. ${ }^{46}$

En cualquier caso Apel reconoció, frente a Heidegger, la necesaria mediación de una pre-estructura transcendental del comprender que se legitima mediante una sistemática articulación entre dos posibles puntos de vista contrapuestos, a saber: por un lado, los rasgos vitales y pragmáticos que definen a cada uno de los usos utilitarios asignados a cada "ente a la mano" en particular; y, por otro lado, a aquellos rasgos comunes históricos y transcendentales

\footnotetext{
${ }^{46}$ A este respecto afirma Apel: "La sugestiva forma heurística de pensar, característica de Ser y tiempo, que se traduce en la reflexión sobre el perfecto 'a priori' del 'pre-ser-se-ya' del 'ser-ahí' como 'ser-en-el-mundo' que se comprende en una situación, inició un nuevo estilo de reflexión transcendental e impidió explicitar el problema de la 'constitución' transcendental, planteado por Husserl, como un problema de 'producciones' subjetivas de una 'conciencia pura'. En realidad es incorrecto desde un punto de vista fenomenológico, hablar de 'construcción' como un acto subjetivo: los fenómenos se constituyen o bien se han constituido ya siempre para nosotros. En nuestros actos subjetivos tenemos que responder ya siempre al mundo constituido -al 'despojamiento' (Lichtung) del 'ahí'-. Esta situación básica del 'pre-ser-se' es de hecho 'irrebasable' y en ella pueden registrarse los factores cuasi-transcendentales de la 'pre-estructura' del comprender; como, por ejemplo, el 'a priori' lingüístico. ¿No es, por tanto, también reconstruible como algo de lo que tenemos que responsabilizarnos? ¿No significa también este 'ya siempre' del perfecto apriorico que hay condiciones de posibilidad del comprender que todavía deben justificarse como condiciones de validez del comprender, de tal modo que, siendo momentos fundamentales de la 'finitud' o del 'estado de yecto' del ser-ahí, no sólo pueden atribuirse sólo a un 'acontecer del ser' o al 'destino del ser'?"' (TF, I, pp. 36-37).
} 
asignados al correspondiente acuerdo entre todas las partes afectadas que subyace tras los anteriores posibles usos utilitarios meramente pragmáticos. Efectivamente, de este modo no se puede garantizar una imposible comprensión del "ser de los entes". Sin embargo al menos se puede justificar el postulado de una comunidad ideal de comunicación con la pretensión de poder alcanzar un "consensus omnium" entre todos los posibles afectados en el ámbito de un "mundo" histórico cada vez más compartido. En cualquier caso, a su modo de ver, ya no se pueden separar ambos aspectos entre sí, como habría pretendido Heidegger inútilmente. ${ }^{47}$

Por eso, Apel opina que la pregunta por el "doble libre sentido" del ente generó en Heidegger una progresiva desviación hacia un progresivo autoenajenamiento de la pregunta por el ser que perfectamente se podría haber evitado. Primero le llevó a conformarse con responder a la pregunta por el "ente" mediante diferentes "dobles libres sentidos" meramente utilitarios que la hermenéutica también puede otorgar al ente. Sin embargo nunca acabó de abordar aquel otro "doble libre sentido" más específico y fundamental respecto al "ser de los entes" en general que inicialmente Heidegger se planteó. Hasta el punto que posteriormente, en un segundo momento, Heidegger se vería obligado a justificar una actitud de permanente cuidado responsable y de ser deudor benevolente, respecto precisamente a aquellos posibles "dobles libres sentidos" meramente utilitarios que ahora se acaban otorgando a los "entes". Se pretende fomentar así una sustitución del planteamiento de la pregunta fundamental mediante la adopción de una actitud meramente ética, que en el fondo responde a meros intereses vitalistas o pragmáticos. Se recoció así implícitamente la necesidad de adoptar una actitud auténticamente histórico-vital y pragmático-transcendental respecto del efectivo destino otorgado de un modo utilitario a cada ente. Sin embargo al formular esta propuesta se superpusieron diversos presupuestos metafísicos sobreañadidos que solo perseguían obscurecer la sustitución operada en el problema abordado. ${ }^{48}$

A este respecto Apel atribuye a Heidegger un progresivo deslizamiento desde la metafísica del ser hacia la hermenéutica del sentido; es decir, un tránsito desde la doble descripción óntico-ontológica de los entes en general hacia otra meramente ética. Es decir, hacia una justificación de la conciencia de fomentar una actitud de cuidado responsable y de sentirse deudor benevolente respecto del resto de los entes, ya sea de una forma individual o compartida. Se trata de un proceso hasta cierto punto inevitable que ahora Apel también comparte, aunque las propuestas de solución de ambos sean totalmente dife-

47 Assmann, J., Violencia y monoteísmo, Barcelona: Fragmenta, 2014.

${ }^{48}$ Apel, K. O., TF, I, pp. 237-238. Cf. Philipse, H., Heidegger's Philosophy of Being. A Critical Interpretation, Princeton: Princeton University, 1998. 
rentes. De este modo Heidegger dejó de tomar progresivamente como término de sus indagaciones la consideración del ser de los entes para fijar su atención preferentemente en el indudable sentido de responsabilidad solidaria - y si se quiere desesperada -, que también cabe adoptar ente los entes, la vida y el ser histórico. Apel justificará así como los "entes" interpelan al "Dasein" de un modo histórico-vital y a la vez pragmático, o si se quiere de un modo pragmático-transcendental, en la medida que se afirma como el único modo posible de evitar las posibles desviaciones, malinterpretaciones o simples círculos viciosos que sin duda se puedan introducir en este mismo proceso. ${ }^{49}$

En cualquier caso Apel se distanció de las propuestas de Heidegger, considerando que al final habría acabado optando por la peor de las alternativas posibles. Se le critica por haber sustituido la relación de "verdad" que inicialmente había establecido entre el "Dasein" y los entes. De hecho habría fomentado una actitud de cuidado responsable y de una conciencia de sentirse deudor benevolente por ante los entes en general, con la única salvedad de proponerse una finalidad histórico-vital que debería estar compartida de un modo pragmático-transcendental. Sin embargo Heidegger utiliza estos principios heurísticos habituales para fomentar unas grandes dosis de dramatismo existencial, sin tampoco llegar a profundizar en los presupuestos últimos que este tipo de procesos conlleva. Especialmente cuando el Dasein se concibe a sí mismo como un ser para la muerte, sin que ya haya ningún lugar para la esperanza, cuando precisamente se debería haber llegado a la conclusión contraria, a saber: el Dasein es un ser para la vida, donde siguen abiertas todas las posibilidades históricas de acuerdo o consenso compartido, sin excluir ninguna. Se objeta así a Heidegger que al eligir esta opción tan desesperada, ya no quede nada de aquella original doble intelección óntico-ontológica que ante todo se debería haber perseguido. En efecto, en la medida que todo ente se concibe junto a otros entes, configurando el autoproclamado "ser de los entes", en ningún momento se debía haber una sustitución de la pregunta por el "ser" por la pregunta por su posible sentido. ${ }^{50}$

Máxime cuando a este respecto Heidegger habría denunciado reiteradamente el olvido sistemático por parte de la metafísica de este tipo de cuestiones ontológicas últimas. En efecto, según Heidegger, en un "pasado" ontológico históricamente ya muy lejano los "entes" se concebía al modo de una simple "cosa", que debería permanecer aislada del resto de los entes, olvidando que todos juntos configuran el "ser de los entes". De igual modo

\footnotetext{
${ }^{49}$ Hiltscher, R., Einführung in die Philosophie des deutschen Idealismus, Darmstadt: WBG - Wissenschafttliche Buchgesellachaft, , 2016.

${ }^{50}$ Tindale, C. W., The Philosophy of Argument and Audiences Reception, Cambridge: Cambridge University Press, 2015.
} 
que se había justificado la inminente pertenencia de todo "ente" a un actual "presente" existencial histórico que certifica la efectiva vigencia de un "ser de los entes". Sin embargo ahora se comprueba cómo, tanto en un caso como en otro, el posible doble libre sentido otorgado por Heidegger al ser queda reducido a un simple proceso colectivo histórico, o simplemente pragmático, sin que ya tenga ningún sentido el recurso a las nociones de verdad o bondad ontológica, como anteriormente él mismo había defendido. Precisamente Apel ahora concibe la radicalización ontológico-existenciaria de la hermenéutica de Heidegger como un tránsito entre dos extremos opuestos, a saber: por un lado, el sentido clásico del ser como entidad verdadera, que de un modo implícito aún está presente en Ser y tiempo; y, por otro lado, esta otra hermenéutica del sentido del ser como mera presencia inminente, como cuidado responsable, como sentido de la deuda contraída, o como mera utilidad pragmática. Sin embargo se sabe de antemano, en este segundo caso, que se trata de distintas pretensiones fracasadas, sin que ya quede ninguna efectiva expectativa ética para la esperanza. ${ }^{51}$

De todos modos ahora se considera que ya Heidegger en Ser y tiempo no siempre habría hecho un uso tan radicalizado de la hermenéutica. Es más, en ocasiones también habría dado entrada a una nueva forma semiótico-hermenéutica-fenomenológica de ver a los "otros", sin reducirlos a simples "cosas". En este contexto tampoco habría considerado que todas las posibles pretensiones de sentido y de verdad estaban fracasadas. En efecto, en la misma medida que se admite una doble comprensión óntico-ontológica acerca de los "entes" en general, también se habría hecho necesario concebir al Dasein como un "ser en el mundo" que a su vez ya no se comprende a sí mismo de igual modo que se concibe a los demás entes al modo de una simple cosa. En su lugar, más bien Heidegger habría concebido al Dasein de un modo semiótico-fenomenológico-hermenéutico como un "ser en el mundo" que, a diferencia de los demás entes, es capaz de asignarse a sí mismo esta capacidad tan singular de reconocimiento que sólo él dispone. De este modo se habría concebido a sí mismo como el "guardián del ser" que a su vez concibe al lenguaje como la "casa del ser". Hasta el punto de concebir a los "otros" Dasein de un

${ }^{51}$ A este respecto afirma Apel: "En esta comprensión del ser como 'por mor de' de la 'cura', desde la que además adquiere sentido lo que llama el 'pasado' ('Vergangenheit') como algo ya inminente ('immer noch bevorstehend'), está la radicalización 'ontológico-existenciaria' de la hermenéutica. Sin embargo, esta (comprensión) [...] no hay que enjuiciarla ante todo de acuerdo con los criterios generalizables de una lógica del lenguaje siempre válida, sino desde el esfuerzo del pensamiento histórico, que en cada situación del mundo ha de realizar continuamente una síntesis entre la anticipación de las posibilidades de la existencia y la apropiación de la tradición" (TF, I, p. 279). 
modo radicalmente distinto al resto de las cosas, sin concebirlos tampoco como un simple "yo" solipsista que subsiste encerrado en sí mismo. ${ }^{52}$

Por su parte Apel, habría dado un paso más. Habría concebido a los "otros" co-sujetos como diversos "seres en el mundo" que igualmente también disponen del lenguaje, pudiendo establecer unas relaciones de interacción semiótica entre ellos. En este contexto Apel atribuye a los "otros" "co-sujetos" una posible comunicación intersubjetiva recíproca, en la medida que todos juntos configuran la estructura transcendental hermenéutica que a su vez hace posible la respectiva comprensión entre las diversas co-subjetividades de los respectivos "seres en el mundo". De todos modos Apel ya no pudo evitar que los distintos cosujetos semióticos se insertaran en dicha estructura transcendental hermenéutica a través de un uso mancomunado del lenguaje, al modo como también ocurre de un modo unilateral en el hombre anónimo inauténtico de Heidegger. En cualquier caso Apel tampoco habría podido admitir una efectiva apertura de la sensibilidad, de la racionalidad, de la voluntad o de la propia ética, así como de los distintos usos cotidianos del lenguaje, respecto de una inalcanzable comunidad ideal de comunicación donde en principio todo este conjunto de facultades se debería remitir, cuando cada una reclama en la práctica un procedimiento autónomo de justificación. A este respecto su noción de co-sujeto hermenéutico mantiene muchas similitudes con la subjetividad postmoderna desestructurada del último Heidegger, por mucho que reiteradamente Apel rechace esta posibilidad. En cualquier caso las propuestas de Apel tendrán un coste evidente: Apel seguiría sin poder garantizar la asignación a dicha cosubjetividad de una efectiva capacidad de comprometerse mancomunadamente respecto de dicha comunidad ideal de comunicación, y no simplemente de un modo consensuado fácticamente diferente. ${ }^{53}$ Pero veamos qué afirma Polo a este respecto.

${ }^{52}$ Bustos, J., La granja humana. Fábulas para el siglo XxI, Madrid: Ariel, 2015.

${ }^{53}$ A este respecto afirma Apel: "Heidegger elude aquí hasta cierto punto el enfoque solipsista de la "filosofía del conocimiento" tradicional a través del 'ser uno con otros'. Mientras la filosofía que parte del sujeto del conocimiento cree tener que constituir el ser de los otros al igual que el ser de las cosas del mundo exterior, como objetos de 'mi conciencia', Heidegger hace valer el punto de vista fenomenológico-hermenéutico según el cual el 'yo', el 'tú' y los 'otros', en cuanto datos concebibles con sentido, se constituyen igual de originariamente desde el 'ser uno con otro' propio de nuestro 'ser en el mundo'; y reconoce además que en nuestra interpretación pública del mundo la precomprensión -conformada de un modo lingüístico tradicional- está siempre anticipada en el modus del 'se' a la capacidad de opinar del individuo, guiando incluso 'inmediata' (zunächst) y 'regularmente' (zumeist) su autocomprensión en el comportamiento medio de la vida cotidiana" (TF, I, p. 254). 


\section{La estructura gnoseológico-realista de la persona-núcleo en Polo}

Por su parte, las propuestas de Heidegger también fueron compartidas y prolongadas por Leonardo Polo (1926-2013) en El acceso al ser-AS- (1962). Aceptó su proyecto programático inicial, aunque simultáneamente trataría de recuperarlo, sin condenarlo precipitadamente al fracaso, como al menos sucede en Ser y tiempo. Por eso trató de insertar a la persona-núcleo en la estructura transcendental de la intelección del "ente", prolongando las propuestas de Heidegger. En este sentido consideró adecuada la doble dimensión óntico-ontológica que, según Heidegger, el hombre auténtico debería asignar a cada uno de los entes. ${ }^{54}$ Por eso discrepa a este respecto con Zubiri, cuando propone una sustitución de la pregunta por el ser por la pregunta respecto de la doble dimensión talitativo-transcendental de la esencia. Pero igualmente discrepa respecto de Apel, cuando propone en su lugar una sustitución por la doble dimensión pragmático-transcendental de la comunicación semiótica. En cualquier caso Polo comparte la separación inicial que Heidegger estableció entre la pregunta por el ser y la pregunta acerca del posible doble sentido del ser, otorgando a esta segunda pregunta una prioridad respecto de la primera. En efecto, la pregunta por el ser es una pregunta previa a la cuestión de la esencia $\mathrm{y}$ al posterior uso del lenguaje, por cuando tanto una como otra presuponen una previa referencia previa al ser. En efecto, según Polo, la pregunta por el ser depende en todo momento aquella previa estructura transcendental entitativa, en la forma óntico-ontológica como había sido descrita por el primer Heidegger en Ser y tiempo. Pero una vez aceptado este punto de partida inicial, entonces debería haber resultado prioritario cuestionarse por el posible "doble sentido" óntico-ontológico que puede a su vez alcanzar el ulterior proceso de intelección del "ente", sin posponer indefinidamente este tipo de cuestiones, como ocurrió en su caso. En cualquier caso, sólo si se acepta un punto de partida así, se podrá determinar desde un principio la dirección correcta a seguir en la búsqueda heurística iniciada mediante la formulación de la pregunta acerca del doble libre sentido del ser, sin quedarse enredado en cuestiones meramente marginales. En todo caso las objeciones se refieren a la lentitud y al permanente retraso a la hora de abordar este tipo de cuestiones, considerando que nunca se ha llegado al momento oportuno de abordarlas. ${ }^{55}$

${ }^{54}$ El presente estudio sobre la noción de sujeto relacional sólo tiene en cuenta las propuestas de Polo en relación con el Dasein heideggeriano en El acceso al ser (1964). Sin embargo hay otros muchos lugares donde después desarrolló más extensamente estas ideas, especialmente en: ¿Quién es el hombre? Un espíritu en el tiempo, Madrid: Rialp, 1993, Curso de teoría de conocimiento, 4 Tomos, Pamplona: Eunsa, 1984-2004; Antropología transcendental, 2 Tomos, Pamplona: Eunsa, 1999-2003.

${ }^{55}$ Goldberg, S. C. (Ed.), Externalism, Self-Knowledge, and Skepticism. New Essays, Cambridge Cambridge University Press, 2015. 
A este respecto, según Polo, Heidegger tampoco terminó por separar de un modo correcto ambas cuestiones, relativas a la legitimidad y a la oportunidad del modo de abordar este tipo de preguntas. Propuso un planteamiento enmarañado al respecto, sin tampoco hacer lo suficiente por evitarlo. Precisamente por no haber distinguido con precisión estos diversos planos inquisitivos, Heidegger acabaría mostrando una gran perplejidad ante las ulteriores consecuencias que se pueden derivar de los sucesivos alargamientos que experimentaron la irresolución de sus propias propuestas. Especialmente cuando se comprueba que se debería poder llevar a cabo una libre deconstrucción en el establecimiento de este tipo de diferencias óntico-ontológicas, cuando en realidad este tipo de cuestiones responden a un plan premeditado donde este tipo de cuestiones ya se había resuelto de antemano. Por ejemplo, se plantea la cuestión del indudable riesgo de sustitución o de simple desviación que se puede derivar por parte del Dasein a la hora de formular la pregunta por el "doble libre sentido" del ser, así como la correspondiente pregunta por el "ser de los entes". Sin embargo en estos casos tampoco se acaba de apreciar que para abordar esta segunda cuestión previamente haya que haber resuelto la primera, si no se quiere fomentar un proceso de autoenajenación cada vez más autodestructivo. De ahí que finalmente Heidegger acabara optando por mantener un calculado equilibrio entre los diversos procesos deconstructivos y reconstructivos que se originan a este respecto, con una consecuencia muy negativa, a saber: No habría acabado de otorgar la prioridad debida a la pregunta por el "doble libre sentido" del ser, tal y como habría sido de esperar, según el programa heurístico previamente establecido. Sin embargo, al final, se acabó pretendiendo resolver precipitadamente la pregunta por el "ente" y por el correspondiente "ser de los entes", sin acabar de comprender que previamente ambas cuestiones se deberían haber articulado adecuadamente. ${ }^{56}$

En cualquier caso, la formulación de este tipo de preguntas exigió una apertura a un horizonte de comprensión cada vez más abierto, que a su vez puede ser objeto de un doble tipo de procesos, a saber: a) los procesos orientados a desentrañar las ilimitadas virtualidades que se pueden atribuir a los múltiples sentidos epistémicos asignados a los entes, en la medida que a su vez se deben remitir al ilimitado horizonte interpretativo del respectivo "ser de los entes"; b) los procesos reflexivos orientados a ejercer un efectivo desentrañamiento de carácter subjetivo acerca del papel que le corresponde al "Dasein" o ser-ahí del existente concreto, en este tipo de procesos. Sólo así se habría podido

\footnotetext{
${ }^{56}$ A este respecto afirma Polo: "Así, pues, la pregunta no 'hace pie' en el concepto del ente. Aquello de quien es el sentido a que la pregunta tiende, tiene que introducirse como un elemento nuevo y distinto del ente. El supuesto, necesario en cualquier caso para formular una pregunta, no puede coincidir con el ente, en tanto que éste posee ya -según su comprensibilidad- un cierto sentido. [...] Aquello de quien es el sentido del ser no puede confundirse con el ente dotado de sentido" (AS, 186 p.).
} 
comprobar como la pregunta por el "doble libre sentido" del ser marca la auténtica dirección que desde un principio se debería haber seguido, sin necesidad de enmarañarse en otras cuestiones previas meramente accesorias. Sólo así el Dasein puede asignarse a sí mismo el papel de ser un "interlocutor" privilegiado o un "pastor" del ser. ${ }^{57}$

Evidentemente, según Polo, Heidegger tampoco reduce el análisis del "doble libre sentido" otorgado al ser al estrecho ámbito de la doble dimensión talitativa y transcendental de la esencia, ni tampoco al mero análisis del doble sentido pragmático y transcendental de la comunicación lingüística, como anteriormente propusieron Zubiri y Apel respectivamente. En efecto, según Polo, Heidegger habría planteado correctamente el análisis del posible "doble libre sentido" que se debería otorgar al ser en la correspondiente hermenéutica existencial de la noción de ente. En su opinión, no habría ninguna necesidad de prolongarla de un modo esencialista o simplemente semiótico, al modo ahora propuesto por Zubiri y Apel. En efecto, sólo si se mantiene el original doble libre sentido óntico-ontológico del término ser, también se podrán determinar aquellas condiciones de posibilidad que permiten llevar a cabo una correcta investigación heurística acerca de la respectiva "autocomprensibilidad" de la noción de "ente", sin tener que recurrir a nociones ajenas a este mismo proceso. De todos modos, Polo opina que nunca se debería haber reservado exclusivamente este análisis a la noción de "existencia" o de "ser de los entes", excluyendo otro tipo de nociones ontológicas igualmente relevantes, como a su modo de ver sucede con la propia noción de "ente". No comparte la opinión de Heidegger de que el análisis del resto de situaciones ónticas $\mathrm{u}$ ontológicas se pudiera volver fácilmente reiterativo y redundante, como se afirmó en su caso respecto de la noción de "ente". Evidentemente, el "ente" siempre mantiene oculto de un modo sobreentendido al "ser", sin tampoco terminar de hacer explícito el enigma de su significado en concreto. Sin embargo tampoco la mera "autocomprensión" de la noción de "ente" permitirá desocultar directamente al denominado "ser de los entes", cuando se trata de un proceso mucho más complejo y parsimonioso. En cualquier caso, se puede afirmar que la "autocomprensión" de la noción de "ente" es la

\footnotetext{
${ }^{57}$ A este respecto afirma Polo: “La pregunta por el sentido del ser es la pregunta fundamental. Esto significa que es la pregunta conductora, es decir, a través de la cual se ve. Naturalmente, este ver ya no consiste en contemplar, intuir o representar, sino, más bien, en una capacidad de dirigir desde lo que yace en la obscuridad a lo patente; es decir, un patentizar-abriendo-y-llegando. A la pregunta pertenece un constitutivo dirigir, ella misma, no precisamente una meta, sino un fondo-que-sale. La pregunta funciona con un régimen heurístico propio, [....] necesita un supuesto, que es su mismo punto de apoyo temático y sin el cual la pregunta no puede nacer en el plano objetivo [...] Heidegger (sin embargo) esquiva esta observación concediendo a la pregunta por el ser conlleva un intrínseco poder desentrañable y desentrañante: la pregunta se dirige al ente, pero como pregunta por el sentido del ente se destaca e independiza de aquel a quien se dirige. Este destacarse marca la auténtica dirección" (AS, p. 184).
} 
mejor estrategia a seguir para evitar la aparición de una situación de perplejidad generalizada, a pesar de que Heidegger se negase a seguirla. ${ }^{58}$

La clave decisiva de la propuesta heideggeriana consistiría más bien, según Polo, en transformar la crítica del sentido en un aliado gnoseológico decisivo en la resolución del problema central que aún hoy día tiene planteado la metafísica, a saber: conseguir que la reiterada recaída del Dasein en la perplejidad se vuelva un factor positivo para la recuperación del dinamismo del saber a favor del realismo, en vez de volverse una rémora a favor del subjetivismo y el agnosticismo. Al menos así habría terminado ocurriendo a su parecer en Ser y tiempo, a pesar de las proclamas heideggerianas en sentido contrario. Según Polo, Heidegger habría llegado incluso a concebirse a sí mismo como un simple hombre anónimo inauténtico, cuando debería haber reaccionado de un modo más propio del hombre auténtico, a saber: utilizando esa creciente perplejidad que ahora genera la aparición de los verdaderos enigmas filosóficos para fomentar un profundo realismo metafísico frente al "ser de los entes" y frente al propio "mundo". Sólo así se habría conseguido evitar la posterior aparición de un sujeto postmoderno desestructurado, como caracterizó al Dasein en su última época. En cualquier caso no se debería recurrir a fáciles unilateralidades más propias del hombre anónimo inauténtico, que sólo sirven para esconder aún más los problemas, como también habría terminado ocurriendo en Zubiri o Apel. En cualquier caso, la reaparición de cualquiera de estas formas de subjetivismo constituye una dificultad fácil de desactivar, según Polo. Máxime cuando el inmanentismo subjetivista ya no se justifica en razones de tipo filosófico, sino más bien en una actitud que a su vez nace de la perplejidad ante la existencia de múltiples libres sentidos contrapuestos, de tipo esencialista o semiótico, sin que haya una necesidad imperiosa de optar necesariamente por uno de ellos. Especialmente cuando se pretende reducir la realidad a una mera presencia mental en cuanto tal o a una mera presencia redundante, como en ocasiones ocurre en Heidegger, sin advertir que el subjetivismo consiste en una mera actitud mental carente de sentido que a su vez gira sobre sí misma en el vacío, sin nada que la sostenga. ${ }^{59}$

\footnotetext{
${ }^{58}$ A este respecto afirma Polo: “Aquello a que se pregunta -'Befragtes'-. Es el ente. Al ente se le pregunta por qué oculta el ser, especialmente según su 'autocomprensibilidad', y no porque en él el ser, poseído, este implícito. Este ocultamiento no puede ser remediado, o, por lo menos, la pregunta no se dirige a remediarlo. Por eso debe estimarse que, en cierto sentido, la indigencia de la autocomprensibilidad del ente es mayor que la de la perplejidad -la función fundante en la zona de la anterioridad a la conciencia-. Limitémonos ahora a notar que esto constituye una grave incongruencia que invalida la distinción heideggeriana entre perplejidad y autocomprensibilidad" (AS, p. 187).

${ }^{59}$ O'Hear, A. (Ed.), "Mind, Self and Person", Royal Institute of Philosophy Supplement: 76, Cambridge: Cambridge University Press, 2015.
} 
DASEIN, PERSONEIDAD, INTERSUBJETIVIDAD Y PERSONA-NÚCLEO (II).

La estructura trascendental intelectiva después de Heidegger, en Zubiri, Apel y Polo

Por el contrario, según Polo, la perplejidad se puede transformar en un poderoso aliado del realismo. Para ello basta con que no se tome como una formula prefabricada de compromiso que permite dar una respuesta indiscriminada a todas las preguntas. Más bien, se debe utilizar para localizar aquel doble libre sentido óntico-ontológico que ahora debe orientar cualquier efectiva afirmación del alcance gnoseológico-realista. Especialmente la que ahora se debe establecer entre los "entes" y el correspondiente "ser de los entes", sin introducir entre ambas nociones contraposiciones que son absolutamente innecesarias. Por eso ahora se recurre a la crítica del sentido para mostrar cómo la perplejidad puede tener una razón de ser verdaderamente edificante. Incluso puede transformarse en un factor decisivo para el desarrollo de una sabiduría propiamente humana que logre un efectivo desvanecimiento y una resolución del preguntar en cuanto tal. De hecho la aparición de un enigma irresoluble siempre hay que tomarlo como un reto que la inteligencia debe afrontar, sin que sirva de nada adoptar una actitud de perplejidad escéptica al respecto. De todos modos, para conseguirlo de forma efectiva, no sólo se debería proponer una justificación meramente retórica y en sí misma precaria. En su lugar se deben aportar pruebas y argumentos verdaderamente decisivos, que hagan irreversible este proceso de resolución del enigma puesto en cuestión. ${ }^{60}$

Evidentemente, por el mero hecho de haber invertido el uso subjetivista hasta ahora dado a la perplejidad no se van a resolver definitivamente los múltiples problemas gnoseológicos ahora planteados por la metafísica. Sin embargo, el giro gnoseológico ahora efectuado permite otorgar un sentido edificante a una perplejidad que sólo generaba una creciente parálisis heurística. Permite otorgar un sentido claramente realista al doble libre sentido óntico-ontológico que Heidegger otorgó al mundo entorno, con independencia de otros posibles sentidos ulteriores que también se le puedan otorgar. En cualquier caso se genera una inversión entre dos planteamientos antitéticos, a saber: por un lado, se parte de una perplejidad gnoseológica generada por una presen-

${ }^{60}$ A este respecto afirma Polo: "A mi modo de ver, en esta incompatibilidad se encierra lo esencial del pleito entre el llamado subjetivismo -el pesimismo gnoseológico- y el realismo. Como actitud, el subjetivismo consagra la perplejidad: es el no llegar a instalarse en la ultimidad. Como tesis desemboca en el agnosticismo. [...] Esta tesis, es tan claramente incongruente, sólo cabe y se mantiene por la actitud. Dicho de otro modo: el subjetivismo como pura actitud es posible -es una actitud-y desde él la última pregunta es hacedera. Hacer tal pregunta significa conferir presencia y vigencia intelectual a la actitud: la pregunta es la formulación del subjetivismo, el arbitrar un sentido a la perplejidad. Tal sentido es sin embargo aparente [...] Entiendo por realismo, no precisamente un sistema que contenga la respuesta a todas las preguntas -la incongruencia de la última dispensa de la tarea-, sino, más en el fondo, la capacidad, propia del saber- de la sabiduría humana -de desvanecer por entero el preguntar. Naturalmente, tal capacidad podría estimarse problemática si dicho desvanecimiento no se muestra logrado, o sólo en precarias condiciones" (AS, 37 p.). 
cia meramente redundante o fáctica; $y$, por otro lado, se concluye alcanzando unas nuevas formas de sabiduría claramente renovada en un sentido realista. Además, ahora se comprueba cómo en una situación similar también se encontraban todas las demás presencias redundantes o meramente fácticas que Heidegger también había rechazado como punto de partida para una ontología fundamental, cuando en realidad su carácter enigmático debería haber demostrado más bien que se trataba más bien de presencias virtuosas. ${ }^{61}$

Por ejemplo, Heidegger exigió que cualquier referencia al "ser de los entes" o al propio "ser del hombre" o a cualquier tipo de presencia en general, debería aportar un lenguaje metafísico adecuado. Sólo así cada Dasein se podría remitir a los "otros" Dasein, sin reducirlos en ningún caso a un "ente" similar a todos los demás. De todos modos, ahora el reconocimiento de la novedad que supone el nuevo punto de vista sapiencial realista acerca de este tipo de presencia indagadora permite referirnos a un conjunto de realidades que anteriormente no tenían una denominación ontológica adecuada. Por ejemplo, permiten remitirse al "mundo en torno" mediante la noción un tanto indefinida de "todo lo demás"; es decir, una referencia implícita o sobreentendida al conjunto de todas aquellas realidades que ahora también presentan una novedad similar; es decir, que no se puede delimitar con absoluta precisión el ámbito que abarcan, pero sin poder tampoco excluirlas como si no se les pudiera asignar ningún tipo de entidad. En este sentido un "mundo" puede significar el Universo, pero también un sinnúmero de ámbitos inabarcables a los que nos referimos como "todo lo demás". En cualquier caso, la noción de mundo así obtenida, como "todo lo demás", no pretende remitirse a un mero conjunto de realidades unificadas por un simple proceso de inclusión, al modo propuesto por Zubiri. En su lugar se trata más bien de un auténtico proceso de abstracción o separación que desde un primer momento se conforma con la obtención de un concepto genérico de "mundo", al modo de un simple "horizonte de comprensión"; solo después, mediante reflexión, se conseguiría una segunda determinación más concreta de dicho "horizonte de comprensión", pudiendo configurar un tipo específico de "mundo" con el mayor grado posible de objetivación, si se hace necesario llegado el caso. ${ }^{62}$

Polo comparte el modo como Heidegger planteó la pregunta por el "doble libre sentido" del ser, aunque a su modo de ver no la acabara de resolver. En

${ }^{61}$ Raedler, S., Kant and the Interest of Reason, Berlin: De Gruyter, 2015.

${ }^{62}$ A este respecto afirma Polo: "Pero la novedad en cuanto referencia matizada según la noción de presencia es la noción de todo lo demás. Todo lo demás es la primera acepción del término mundo. En el mundo significa: introducción de la presencia sin inclusión (recuérdese que la presencia se suscita en antecedencia). A esto llamamos abstracción. La abstracción como determinación directa es la obtención. La determinación segunda, refleja, es la consecución" (AS, pp. 116-117). 
su opinión, Heidegger tampoco terminó de abordar la pregunta fundamental que originariamente se había planteado cuando se interrogó por el modo de ser de cada "ente" en general y por el "ser de los entes" en especial. En efecto, para Polo la pregunta por el "doble libre sentido" del ser precede de algún modo a la pregunta por el ser, haciendo posible que esta última pregunta se dirija específicamente a su objeto propio, sin quedarse enmarañada en cuestiones accesorias, como a su modo de ver terminó ocurriendo en Heidegger. En este contexto, la pregunta por el "doble libre sentido" del ser debería haber permitido resolver las objeciones que anteriormente se formularon a este tipo de propuestas óntico-ontológicas. Deberían haber permitido mostrar que es posible orientar este tipo de preguntas en la dirección correcta hacia el "ser de los entes", sin que ello suponga generar ningún tipo de violencia o manipulación al respecto. Especialmente, cuando se comprueba que a través del análisis del "ente" se puede dejar entrever el "ser de los entes", en la medida que el Dasein se afirma como el único principio relacional intelectivo capaz de abordar este tipo de cuestiones. Hasta el punto que ahora sería posible abrirse paso de nuevo desde los entes en general hasta el "ser de los entes" en especial, sin tampoco tener que poner límites o diferencias arbitrarias a este proceso de ilimitada ampliación de horizontes interpretativos, al modo como acabó ocurriendo en Heidegger. ${ }^{63}$

En cualquier caso, Polo comparte totalmente la opinión de Apel de que Heidegger se habría deslizado progresivamente desde una metafísica del ser hasta una hermenéutica del sentido; es decir, hacia una hermenéutica de horizontes cada vez más indefinidos donde tiene cabida la reflexión acerca de la temporalidad de la vida y del ser histórico, o de la utilidad de los propios "entes a la mano", sin tampoco establecer una clara diferencia entre ellas, al modo como anteriormente ya fue indicado por él mismo. En este sentido, Polo también reconoce que Heidegger reduce el sentido del ser a un mero cuestionamiento de la mera relación de cuidado responsable y de ser deudor benevolente. Es decir, unas relaciones que por razones pragmáticas o utilitarias el "Dasein"

\footnotetext{
${ }^{63}$ A este respecto afirma Polo: "Todo saber basado en la estabilidad y suficiencia de su punto de partida [...], concibe este mismo punto de partida como base 'firme' -o sea, impenetrable-, que acota la profundidad de lo que puede ser descubierto desde él. El carácter fundamental de la pregunta por el ser es muy distinto. En esta pregunta, y sólo en ella, el punto de partida comprensible -el ente- no funciona como fundamento suficiente, puesto que justamente se pregunta por el sentido del ser, en lugar de explorar racionalmente a partir de lo ya estabilizado como comprensible. [...] En la pregunta por el sentido del ser, en cambio, el fundamento no antecede como base, sino que se ejerce en la pregunta misma y no de un modo estático. [...]. El supuesto, necesario en cualquier caso para formular una pregunta, no puede coincidir con el ente, en tanto que este ya posee -según su comprensibilidad- un cierto sentido. En orden al planteamiento de la pregunta por el sentido del ser, la autocomprensibilidad del ente debe ser reducida a una situación de extrema trivialidad, por cuanto cualquier sentido ya poseído no puede ser el sentido al que tiende la pregunta"' (AS, 184-185).
} 
mantiene con los demás entes más próximos que le rodean. Sin embargo, se objeta que en este contexto más intersubjetivo o relacional tampoco hubiera acabado de abordar la pregunta por el ser, como hubiera sido de esperar. En este sentido, Heidegger habría establecido una clara diferencia entre aquel posible despejamiento del "ser de los entes" y esta otra actitud existencial de concebirse como una permanente conciencia de "cuidado responsable" y de "ser deudor" benevolente ante cada uno de los entes en general y el "ser de los entes" en particular. Además, él mismo habría sido el primero en prohibir cualquier posible deslizamiento entre ambas cuestiones, desde las cuestiones estrictamente metafísicas a las meramente éticas. Sin embargo también habría sido él mismo el primero en no respetar este tipo de demarcaciones. En cualquier caso, Heidegger habría establecido una diferencia muy clara entre la verdad del fundamento y la posterior trivialidad de la mera sucesión temporal de eventos históricos en sí mismos efímeros, cosa que tampoco Apel parece advertir. ${ }^{64}$

Heidegger recurre en estos casos al método de la pregunta que gira de un modo redundante y reiterativo alrededor de la estabilidad y suficiencia que indudablemente suscita la pregunta por el "doble libre sentido" del ser, aunque sin tampoco querer provocar innecesarias complicaciones posteriores. De todos modos, en su caso esta estrategia tampoco le supuso un auténtico avance heurístico en la investigación planteada. En su lugar más bien le exigió un permanente anclaje en la trivialidad del respectivo punto de partida. Ni accedió a un efectivo conocimiento de la estructura óntica de los diversos entes en particular, incluidos ahora también los respectivos Dasein. Ni tampoco reconstruyó la estructura ontológico-transcendental del correspondiente "ser de los entes". En su lugar, se quedó más bien en el mero reconocimiento del posible doble sentido óntico-ontológico que todo ente puede tener, sin pretender afirmar nada más, a diferencia de lo que inicialmente había programado. ${ }^{65}$

De todos modos, según Polo, podría no haber ocurrido así. Para eso hubiera bastado que el afán de saber se hubiera reconducido de un modo gnoseológico hacia el descubrimiento de aquel tipo de fundamento que en cada caso se considere suficiente para garantizar una resolución realista de las diferentes cuestiones planteadas. De haber seguido esta estrategia heurística, también se hubiera

\footnotetext{
${ }^{64}$ A este respecto afirma Polo: “Para Heidegger el ente es impenetrable, meramente encontrado y manejable de un modo utilitario: el encuentro del ente no pasa de permitir contar con él. Desde el ente significa (para el hombre): el encuentro de lo susceptible de uso cuidadoso (en el sentido de lo que llamábamos solución). El cuidado es función de la perpleja apertura al ser, pero se distingue de ella en que no es estrictamente fundamental y, por tanto, se desliza fácilmente hasta la trivialidad. [...] Para Heidegger la conciencia humana es la vigilia del cuidado" (AS, pp. 187-188).

${ }^{65}$ Kreines, J., Reason in the Word. Hegel's Metaphysics and Its Philosophical Appeal, Oxford: Oxford University Press, 2015.
} 
podido lograr un mayor avance con la máxima ganancia posible. Todo ello, a pesar de tener que ir paso a paso, sin pretender abordar directamente el fondo de la cuestión en cada caso propuesta, como con frecuencia le sucede a Heidegger. En cualquier caso, se trata de un segundo procedimiento gnoseológico realista propuesto por Polo totalmente distinto al método de la perplejidad óntico-ontológica que propone Heidegger. Justo por ello, Polo le objeta que pretenda incrementar al máximo la separación existente entre los meros interrogantes vulgares y el afán de saber propiamente filosófico. Especialmente cuando ya sabía de antemano que tampoco iba a poder poner ya nunca un punto final a sus programáticas pretensiones heurísticas de avance y ganancia. ${ }^{66}$

En cualquier caso, Polo opina, en contra de Apel, que el punto de partida de la metafísica hermenéutica de Heidegger está en las antípodas del propuesto por la filosofía crítico-transcendental, ya sea en Descartes, Kant o Hegel. El punto de partida de Heidegger no es el saber ni la presencia. Su punto de partida es la estricta situación de perplejidad generalizada donde deliberadamente el "Dasein" pretende instalarse. Desde una situación tan problemática resulta imposible llevar a cabo lo que Apel propone. No es posible pretender llevar a cabo, desde allí, un análisis de las condiciones de posibilidad de la propia crítica de sentido, incluida ahora también la propia noción de "ente", de "vida" o de "ser de los entes", de "ente a la mano", de "ente útil", cuando, bien mirado, se trata de un imposible metafísico. Máxime si se tiene en cuenta que la aparente facilidad con que se pretende reiterar la pregunta fundamental acerca del "ente" también puede ser en este caso engañosa. De hecho las referencias al "ente" sólo se pueden justificar como un simple indicio de la enorme facilidad con que también se puede generar una situación de perplejidad en sí misma estéril y paralizante. En cambio, según Polo, sólo la localización del auténtico fundamento del "ser" hubiera permitido evitar este tipo de reiteración redundante de una perplejidad en sí misma estéril. Sólo a partir de un fundamento sólido se hubiera podido llevar a cabo una investigación heurística que nunca se detenga, sino que continuamente avance. De todos modos, éste ya no fue precisamente el horizonte hermenéutico donde se instala la perplejidad generalizada fomentada por Heidegger en Ser y tiempo desde un comienzo. Por eso, según Polo, Heidegger acabó cerrando la única vía de salida que aún quedaba abierta. ${ }^{67}$

${ }^{66}$ A este respecto afirma Polo: "La pregunta se distingue netamente de la conducción del saber en la forma inductiva o deductiva. Todo saber en la estabilidad y suficiencia de su punto de partida tiene de antemano limitada su capacidad de avance y de ganancia, justamente por la suficiencia de su fundamento, el cual no puede ser penetrado en cuanto tal, sino tan sólo determinado y explotado consecutivamente. El punto de partida, como base 'firme' -o sea, impenetrable, acota la profundidad de lo que puede ser descubierto por él" (AS, p. 184).

${ }^{67}$ A este respecto afirma Polo: "Ahora bien, con esto renunciamos a la tarea de salir de la perplejidad en el preciso sentido de declararla ilegítima, y, a la vez, insuficiente para el saber, 
Por otro lado, hay un segundo punto donde Polo discrepa abiertamente respecto de las propuestas de Apel. En su opinión, en Ser y tiempo nunca se pretendió llevar a cabo una efectiva ampliación de la filosofía crítico-transcendental al modo kantiano. Apel pretende incluir en este contexto los análisis de Heidegger acerca de las condiciones de posibilidad de la crítica del sentido. Sin embargo, según Polo, el fundamento que busca Heidegger para la metafísica a través de la crítica del sentido pretende iniciar una reflexión acerca de las condiciones de posibilidad del propio ser, no del conocimiento, aunque después fracase en su intento. Hasta el punto que ahora la crítica de sentido no sólo afectaría al propio ente, sino también al pensamiento, al lenguaje y a las distintas formas de comunicación, pero no a la inversa. Sólo así, todas estas manifestaciones del ser, se podrían abrir a un horizonte de comprensión todavía más amplio que el planteado de un modo inmanentista por la anterior filosofía del sujeto transcendental. Al menos, así sucede con los diversos tipos de "a priori", "preestructuras", "constitución de sentido" a los que anteriormente, según Apel, Heidegger se remite. Sin embargo, Polo considera que este tipo de propuestas crítico-transcendentales acaban generando los mismos problemas que antes se trataban de evitar, manteniendo una postura claramente discrepante al respecto. Se volvería así a fundamentar el carácter transcendental de la "pre-estructura hermenéutica del comprender" en virtud de una crítica fenomenológica del sentido ya definitivamente dada y configurada. Sin embargo ahora una crítica de sentido de este tipo debería tener todas las alternativas de solución abiertas, sin excluir ninguna, incluida especialmente la ontológica. ${ }^{68}$

En efecto, se pretende otorgar a la crítica del sentido un valor de anticipación superior respecto del concepto, como si se tratara de determinar las condiciones de posibilidad ónticas y ontológicas para que este último pudiera tener lugar. Sin embargo, de aceptar este planteamiento, también se volvería a plantear el dilema transcendental antes analizado, pero nunca resuelto, a saber: se debería volver a justificar la anterioridad del entender respecto de lo entendido, para volver a concluir lo ya antes dicho: sin entender no puede haber entendido, de igual modo que sin referencia a los conceptos ontológicos tampoco puede haber auténtica crítica de sentido. En efecto, por mucho que la crítica de sentido se justifique en virtud de una "pre-estructura del comprender" que inevitablemente siempre tendrá un carácter subjetivo, los conceptos siempre pretenderán anticiparse con un carácter ontológico claramente objeti-

la noción de dependencia fundamental. De ello nos debe convencer ya la perplejidad. La perplejidad es fondo inalterable, carente de expansión. Lo inalterable de la perplejidad está en su reiterabilidad, según la cual la pregunta fundamental es hacedera. Lo hacedero de la pregunta invalida el intento de referir el saber a un fundamento desde el que se constituya de manera absolutamente reflexiva" (AS, p. 47).

68 Alznauer, M., Hegel's Theory of Responsibility, Cambridge: Cambridge University Press, 2015. 
vo por tratarse de una condición de posibilidad y de sentido de este mismo proceso de comprensión, y no a la inversa. En cualquier caso, la reflexión crítico transcendental al modo de Apel siempre debe revertir en estos casos en una fundamentación semiótica de tipo igualmente subjetivo. De este modo tampoco se podrá ya pretender evitar la aparición de nuevo del espectro de la perplejidad, cuando justamente se pretendía evitar este tipo de situaciones. En cualquier caso, ésta es la enseñanza que Polo quiere extraer de Heidegger, aunque finalmente el propio Heidegger acabará orientando sus propuestas en una dirección totalmente distinta. ${ }^{69}$

A este respecto, Polo quiere ver en las propuestas de Heidegger una reincidencia de ciertos estereotipos hegelianos a la hora de concebir la intersubjetividad del "yo". En todo caso, Heidegger concibe el Dasein de "uno mismo" como una reduplicación de los "otros" Dasein con los que a su vez interactúa, al modo como también propuso Hegel. En todos estos casos la mismidad del propio Dasein se aborda como si se tratara de una mera reduplicación anónima del "otro" Dasein. En cualquier caso no se utiliza esta misma relación interpersonal como punto de partida para llevar a cabo una profundización en el análisis de las relaciones de alteridad. En ningún caso se deberían reducir a un simple modelo reduplicativo, debido al carácter irreductible que, según Polo, presentan las ilimitadas posibilidades de crecimiento asintótico de los respectivos principios intelectivos. No se comprende cómo en estos casos la reflexión sobre uno mismo puede reducirse a la atribución de una similar estructura transcendental hermenéutica, que a su vez se mueve simplemente al nivel categorial propio de los entes a la mano a los que habitualmente se remite el lenguaje ordinario. Por eso, tampoco Heidegger -o después Apel- se plantean cuestiones de mayor calado relativas a la constitución de uno mismo y del correspondiente ser personal, así como del correspondiente núcleo del saber, como ahora propone Polo. ${ }^{70}$

En cualquier caso, Polo considera que ya no se puede concebir a las "otras" personas-núcleo como una simple copia o imitación de las respectivas formas de saber acerca de uno mismo. En su lugar se debería reconocer que cada persona-núcleo tiene una forma irreductible de operar, que se debe legitimar por sí misma. Sin embargo en Heidegger sigue siendo posible concebir a los "otros" Dasein, incluido a "uno mismo", como si se trata-

${ }^{69}$ A este respecto afirma Polo: “Esto equivale a decir que el objeto no es el yacimiento primario de lo inteligible, o un dato ofrendado a la mera contemplación, sino que en él lo inteligible aparece en tanto que una clave antecedente y sobre la que se puede volver, hace inútil toda apropiación: entre el entender y el entendido, la prioridad corresponde al primero: entendido se dice en virtud del entender, y no al revés. La subjetividad del saber se confunde con el fundamento transcendental" (AS, p. 44).

70 Segalerba, G., Semantik und Ontologie, Drei Studien zu Aristoteles, Bern: Peter Lang, 2015. 
ra de una simple reduplicación imitativa igual a los anteriores Dasein. En Heidegger no se acaba de apreciar el carácter irreductible de cada Dasein respecto de los "otros" Dasein. Con el agravante de que posteriormente Heidegger, Zubiri y también Apel, pretenden seguir aplicando este mismo modelo meramente mecánico o simplemente animal a la correspondiente estructura transcendental intelectiva-hermenéutica del conocimiento humano, así como a la propia comunicación lingüística interpersonal. Se proyecta en ambos casos un modelo reiterativo meramente imitativo en sí mismo anónimo. No se advierte que, de admitir un modelo de este tipo, se fomentaría una actitud claramente reduccionista que sería incapaz de justificar muchas de las virtualidades que ahora se asignan al conocimiento humano y a la comunicación lingüística intersubjetiva. ${ }^{71}$

Por su parte, Polo enfatiza el carácter irreductible e irremplazable de la estructura transcendental intelectiva que a su vez configura la persona núcleo. De ahí que tampoco pueda ser sustituida de un modo mecánico o animal por "otra" simple reduplicación imitativa anónima que trate de hacer sus veces. A este respecto se considera que la estructura transcendental intelectiva está sujeta a un proceso de sucesivas ampliaciones mediante las que se puede incrementar el múltiple conjunto de elementos entitativos que en cada caso se tienen en cuenta, sin que ya se pueda poner un límite a este mismo proceso. En cualquier caso, dicha estructura tampoco puede ser el resultado de la suma de simples homogeneidades miméticas anónimas, como habría sucedido en el caso de Hegel o de Heidegger, Zubiri o Apel. En su lugar más bien la estructura transcendental intelectiva se concibe como el resultado de una multiplicidad de componentes irreductibles entre sí, donde cada elemento tiene un significado específico propio, ya verse sobre el conocimiento de los primeros principios, sobre el conocimiento objetivo de los correspondientes conceptos de la mente humana o sobre la propia persona-núcleo que a su vez articula estas distintas formas de saber. Se trata, en

\footnotetext{
${ }^{71}$ A este respecto afirma Polo: “El ser-ahí (en Hegel) 'no es lo que es por sí mismo' (I, p. 115). Precisamente su determinación consiste en ser otro, Otro es introducido como determinación según su significación, inidéntica o irreductible a la suposición de uno, es decir, a la situación anterior a la introducción. Por eso se dice enseguida que Etwas u otro son 'una y la misma cosa', para la 'reflexión exterior' o meramente comparativa, que no penetra sino que se limita a proceder mediante cambios de la atención únicamente. Cuando se hace jugar el dinamismo del pensar, se ve que "otro no es otro que Etwas sino en sí, 'otro de sí mismo' (I, p. 105). [...] De este modo otro verifica su noción en cerrada no duplicidad de supuestos. Es decir, en el seno de su proceso que tiende a comparecer: estricta inidentidad hegeliana. 'El otro por sí es el otro por relación a; así pues, el otro de sí mismo, el otro del otro, por lo tanto, lo que es desigual en sí, lo que se niega, lo que varía' (I, p. 106). Pero con ello se logra y verifica el pensar-lo. 'Etwas se conserva, subsiste en su ser ahí: forma esencialmente uno consigo y no menos esencialmente no forma uno consigo' (I, p. 106). Ser-ahí sólo renace en el subsistir de su negación, no es dejado al margen de ella, inalcanzado por ella. Es así como entra en relación consigo. Lo que subsiste sin ser dejado es lo que Hegel llama momento" (AS, pp. 237, 238).
} 
DASEIN, PERSONEIDAD, INTERSUBJETIVIDAD Y PERSONA-NÚCLEO (II).

La estructura trascendental intelectiva después de Heidegger, en Zubiri, Apel y Polo

cualquier caso, de tres principios irreductibles que hacen posible la estructura transcendental intelectiva, sin poderlos ya concebir como una mera imitación de "otro" simulacro previo, como ocurría en los tres casos anteriormente señalados. ${ }^{72}$ Pero una vez analizados los cuatro autores en cuestión, pasemos ya a las conclusiones.

\section{Conclusión: ¿tuvo la estructura transcendental intelectiva una dimensión deliberativa?}

Evidentemente, Zubiri, Apel y Polo admitieron la estructura transcendental intelectiva que, según Heidegger, hace posible la comprensión del "ser de los entes" en general y de cada uno de los entes en concreto. Pero a su vez estos distintos autores también mantuvieron numerosas discrepancias a la hora de concebir estos diversos sujetos relacionales epistémicos. Se les atribuyó un carácter quiddidativo-transcendental o pragmático-transcendental, con la pretensión de evitar el carácter óntico-ontológico que inicialmente al menos se le había asignado, pero sin lograr asignarles la amplitud de horizontes que inicialmente se pretendía. ${ }^{73}$ Se han examinado a este respecto cuatro casos.

a) Heidegger justificó una posible apertura a la duplicidad de "libres sentidos" que de un modo óntico-ontológico el Dasein puede otorgar a los entes, según adopte una actitud anónima o claramente auténtica. En este contexto, el propio Dasein se afirmó inicialmente como un "ser en el mundo" con una capacidad de reduplicar mancomunadamente sus respectivas correlaciones que a su vez mantiene con el "ser de los entes", atribuyéndose así una trans-

\footnotetext{
72 A este respecto afirma Polo: "A la necesidad de ampliación transcendental sirve la consideración del conocimiento humano. En orden a esta cuestión, el conocimiento humano se ofrece como un múltiple conjunto. Lo múltiple del conjunto estriba en que es más que el principio transcendental. Ser más, aquí, es la indicación de más, es decir, que sirve a la ampliación transcendental. Ahora bien, la penetración y el esclarecimiento de lo múltiple del conjunto, en cuanto que carácter de más, debe hacerse en la forma de una enérgica remoción de toda homogeneidad La amplitud transcendental no tiene sentido de generalidad [...]. La multiplicidad de momentos ha de ser descrita, por lo pronto, como multiplicidad de irreductibles. La irreductibilidad no significa en modo alguno equivocidad, puesto que sirve a la necesidad de una ampliación transcendental. [...] El conocimiento del principio y el conocimiento objetivo son irreductibles. Pero hay todavía un tercer irreductible en orden a la multiplicidad del conocimiento: lo que he llamado núcleo del saber. [...] Desde el punto de vista del principio transcendental, la irreductibilidad se debe a que el principio transcendental no es único. La irreductibilidad significa en este caso, por lo tanto, que el conocimiento no puede ser explicado desde un principio, que habría de ser único; y, sin embargo, no por ello se desvirtúa su valor transcendental de la principialidad. Aquí la multiplicidad sugiere riqueza, abundancia y no división, mutua oposición o anulamiento recíproco" (AS, p. 247-248).

${ }^{73} \mathrm{Gnau}, \mathrm{D} .$, Person werden. Zu Wesen und Benstimmung des Menchen in der Theologie von Panagolis Nellas, Christos Yannaras und Ioannis Zizioulas, Würzburg: Echter, 2015.
} 
cendentalidad que de otro modo hubiera sido imposible. Sin embargo el mismo acabó declarando la imposibilidad de llevar a cabo este mismo proyecto programático, defendiendo en su última época la aparición de una subjetividad postmoderna cada vez más desestructurada. ${ }^{74}$

b) Zubiri justificó una posible apertura a una duplicidad de "libres sentidos" que la persona, o más bien la personeidad, puede asignar de un modo talitativo-transcendental a los entes. En este contexto, la personeidad se define como un animal de realidades con capacidad de reduplicarse anónimamente, al modo como ahora también sucede con este tipo tan peculiar de animales personales, atribuyéndose así una transcendentalidad que de otro modo sería imposible. Sin embargo el mismo exigió la referencia a una inteligencia sentiente que ahora se reafirma como un requisito imprescindible para poder llevar a cabo este proyecto programático, sin que ya sea posible la referencia a una plena transcendentalidad de la globalidad de las esencias, como en principio se pretendía. Es más, de este modo restringiría de un modo innecesario su horizonte interpretativo, resultando imposible mejorar la inicial transcendentalidad pretendida, teniéndose que conformar más bien con la localización de diversas quiddidades utilitarias meramente diferentes ${ }^{75}$.

c) Apel también justificó una apertura a una duplicidad de "libres sentidos" que los diversos "co-sujetos" comunicativos pueden asignar de un modo pragmático-transcendentales a los entes. En este contexto, cada "co-sujeto" comunicativo se define como un "otro" interlocutor de rasgos similares, con una capacidad de abrirse al postulado de una comunidad ideal de comunicación que ahora se reafirma como un requisito imprescindible para poder alcanzar un "consensus omnium" entre todos los posibles interlocutores afectados. Sin embargo el mismo justificaría esta propuesta en virtud de unos planteamientos crítico-transcendentales donde se haría inevitable la reaparición de las conocidas objeciones de la filosofía transcendental a una posible apertura al "ser de los entes". De este modo se desvanecería su inicial pretensión programática de abrirse a una comunidad ideal de comunicación aún más abierta, teniéndose que conformar más bien con el logro de diversos acuerdos consensuados fácticos meramente diferentes. ${ }^{76}$ Finalmente,

d) Polo también justificó una posible apertura a la duplicidad de "libres sentidos" que la persona-núcleo puede asignar de un modo gnoseológico-realista a los entes a través de las distintas formas de saber. Se pretendió recuperar así el sentido inicial que el primer Heidegger quiso otorgar a la doble di-

\footnotetext{
74 Braidotti, R., Lo Posthumano, Barcelona: Gedisa, 2015.

${ }^{75}$ Cortina, A.; Serra, M-A., ¿Humanos o posthumanos? Singularidad tecnológica y mejoramiento humano, Barcelona: Fragmenta, , 2015.

${ }^{76}$ Wallraff, M. (Hg.), Geschichte als Argument? Historiographie und Apologetik, Leuven: Peeters, 2015.
} 
mensión óntico-ontológica de los entes en Ser y tiempo, así como el sentido originario que se quiso dar a la noción de hombre auténtico. En este contexto se hace notar como la persona núcleo podría localizar un horizonte crítico de sentido con unas pretensiones de intelección cada vez más amplias e irreductibles, en la medida que persigue un pleno desarrollo de sus facultades sensitivas, racionales, especulativas, volitivas, éticas o simplemente lingüísticas. Justo por ello, simultáneamente se discrepa del progresivo distanciamiento que el último Heidegger adoptó frente a su propia noción inicial de Dasein. Sólo le sirvió para defender una noción de subjetividad postmoderna cada vez más desestructurada y alejada de este tipo de pretensiones. ${ }^{77}$

Evidentemente, también es posible establecer una complementariedad entre estas distintas propuestas de Heidegger, Zubiri, Apel y Polo, como se ha sugerido en la presentación de este artículo. De hecho Polo pretende fundamentar de un modo todavía mejor una propuesta que al final el propio Heidegger consideró de imposible ejecución. En este sentido Polo propone un desarrollo específico de la teoría de los hábitos intelectuales, que Heidegger nunca desarrolló. Por su parte, Zubiri y Apel prendieron prolongar un conjunto de propuestas que el primer Heidegger de Ser y tiempo habría considerado factibles. Al menos así sucede con el recurso a la esencia o a un uso cotidiano del lenguaje, que el propio Heidegger fomentó una vez comprobado el fracaso se su inicial proyecto programático. Sin embargo, finalmente también acabaría progresivamente distanciando de estas propuestas, para dar entrada en su última época a una subjetividad postmoderna cada vez más desestructurada. En cualquier caso los cuatro autores tuvieron formas muy distintas de concebir sus respectivas nociones del sujeto epistémico relacional, ya se le denominase Dasein, personeidad, co-subjetividad, o persona-núcleo, aunque compartieran de un proyecto programático común. Y en esa misma medida, también admitieron una estructura transcendental hermenéutico-intelectiva, que le permitiera justificar la validez de un saber discursivo compartido acerca del "ente" entre los diferentes sujetos epistémicos relacionales afectados, Sin embargo formularon esta propuesta desde postulados de tipo esencialista, semiótico o simplemente gnoseológico muy diferenciados. Se planteó así una alternativa, a saber: o bien se establece una relación meramente anónima y desestructurada entre todos ellos, como finalmente parecen proponer Heidegger, Zubiri y Apel; o, por el contrario, se considera que toda persona auténtica debe fomentar una actitud de apertura realista a los entes en general y al "ser de los entes" en particular. Máxime cuando se comprueba que una relación transcendental de este tipo ya no se puede fundamentar en la mera relación epocal simplemente anónima que se puede establecer repetitivamente entre "una" esencia y

77 Grygiel, S., Discovering the Human Person. In Conversation with John Paul II, Grand Rapids (MI): W. B. Eerdmans, 2014. 
"otra" esencia o entre "un" Dasein y "otro" Dasein, al modo postulado por Hegel. En su lugar, más bien una relación transcendental de este tipo se debería poder justificar en virtud de una plena integración habitual entre los diversos principios epistémicos de tipo sensible, intelectivo, racional, volitivo, ético o simplemente lingüístico, al modo como ahora propone Polo. ${ }^{78}$

Evidentemente, no se trata ahora de analizar las posibles ventajas e inconvenientes que se podrían derivar de cada una de estas propuestas. Sin embargo, sí parece relevante resaltar un factor que ha estado sobreentendido a lo largo de toda la exposición y que, como sucede con la libertad humana, todavía no se ha podido tener en cuenta. $Y$ en este sentido siempre cabe preguntar: ¿Formaron parte las libres deliberaciones voluntarias de la correspondiente estructura transcendental intelectiva o simplemente se quedaron al margen? En cualquier caso, se trata de una cuestión propedéutica muy compleja, que deberá ser analizada más pormenorizadamente en otro lugar. ${ }^{79}$

\footnotetext{
${ }^{78}$ KärkKÄInEn, V.-M., Creation and Humanity, Vol. 3, Grand Rapids (MI): Willian B. Eerdmans, 2015. ${ }^{79}$ Ortiz de Landázuri, C., "El Dasein, la personeidad, el co-sujeto y la persona-núcleo (III). La estructura transcendental deliberativa después de Heidegger, en Zubiri, Apel y Polo", inédito.
} 